Preprints of the

Max Planck Institute for

Research on Collective Goods

Bonn 2008/22

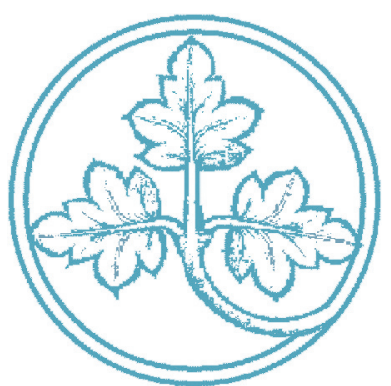

Komplexität und

Normenklarheit

- oder: Gesetze sind für Juristen gemacht

Emanuel Vahid Towfigh

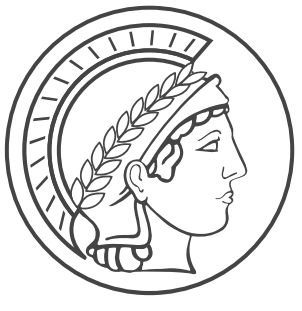




\title{
Komplexität und Normenklarheit - oder: Gesetze sind für Juristen gemacht
}

\author{
Emanuel Vahid Towfigh
}

May 2008

Erschienen in:

Der Staat 1/2009, S. 29 ff. 


\section{Komplexität und Normenklarheit \\ - oder: Gesetze sind für Juristen gemacht}

\section{Emanuel Vahid Towfigh ${ }^{*}$}

I. Einleitung 2

II. Komplexität $\quad 3$

1. Definition 4

2. Wirkung 6

3. Perspektive 27

4. Reduktion $\quad 8$

III. Normenklarheit $\quad 9$

1. Verfassungsrechtliche Herleitung 10

2. Inhalt 11

$\begin{array}{ll}\text { a) Normen } & 11 \\ \text { b) Klarheit } & 12\end{array}$

c) Relativierung $\quad 12$

3. Bezugspunkt 14

$\begin{array}{lr}\text { IV. Kritik } & 15\end{array}$

1. Verfassungsrechtliche Herleitung 16

2. Inhalt 17

3. Bezugspunkt 17

a) Realität: Gesetzeskenntnis und Rechtsverständnis der Bürger $\quad 18$

b) Theorie: Wirkungsweise des Rechts $\quad 21$

c) Ökonomie: Kosten der Komplexität und »optimale Komplexität« 24

d) Verhalten: Reaktionen auf Komplexität 26

e) Dogmatik: Objektivierte Adressatensicht $\quad 27$

aa) Adressatensicht $\quad 28$

bb) Objektivierung $\quad 28$

f) Lex lata: unklare und unbekannte Normen $\quad 29$

V. Vorschlag $r$

$\begin{array}{ll}\text { 1. Verfassungsrechtliche Herleitung } & 31\end{array}$

a) Demokratie 31

b) Gewaltenteilung $\quad 32$

c) Grundrechte $\quad 34$

2. Inhalt $\quad 35$

3. Bezugspunkt 36

a) Reduktion der Komplexität $\quad 37$

b) Verfassungsrechtliche Gründe $\quad 37$

c) Größere Realitätsnähe $\quad 38$

d) Ökonomische und verhaltenswissenschafliche Argumente $\quad 39$

e) Höhere Konsistenz der Gesamtrechtsordnung $\quad 39$

f) Rechtsschutz $\quad 40$

$\begin{array}{lr}\text { VI. Ausblick } & 40\end{array}$

Dr. iur., wissenschaftlicher Referent am Max-Planck-Institut zur Erforschung von Gemeinschaftsgütern, Bonn. Der Verfasser dankt für vielfältige Anregungen Dr. Stefan Bechtold, PD Dr. Martin Beckenkamp, Dr. Felix Bierbrauer, Nadine Bläser, Prof. Dr. Christoph Engel, Dr. Andreas Glöckner, Regina Goldschmitt, Dr. Jörn Lüdemann, Dr. Stefan Magen, Alexander Morell, Prof. Dr. Janbernd Oebbecke, Dr. Niels Petersen, Dr. Katharina Towfigh. Die verbleibenden Fehler sind natürlich meine. 


\section{Einleitung}

Es ist ein seit Jahrzehnten in Politik und Gesellschaft gepflegtes ceterum censeo, die zunehmende Komplexität der Lebenssachverhalte zu bedauern und die mit ihr verbundene zunehmende Komplexität des Rechts zu geißeln. ${ }^{1}$ Prominentestes Beispiel ist das Steuerrecht ${ }^{2}$, daneben gelten aber etwa auch das Umwelt- und Technikrecht, ${ }^{3}$ das Bilanzrecht, ${ }^{4}$ das Unterhaltsrecht ${ }^{5}$ und Teile des Sozialrechts ${ }^{6}$ als aufgrund ihrer Komplexität kaum handhabbare Regelungsmaterien. Eine der Antworten des Rechts auf seine unverkennbare Neigung ${ }^{7}$ zur Komplexität ist das vom Bundesverfassungsgericht schon in einer seiner ersten Entscheidungen entwickelte Erfordernis der »Normenklarheit«. ${ }^{8}$ Komplexität, so kann vor der Folie dieses Grundsatzes nach heutiger Dogmatik formuliert werden, ist unschädlich, solange verständlich bleibt, was die Norm von ihrem Adressaten verlangt. Gleichzeitig wird der Verpflichtung zur Verständlichkeit disziplinierende Wirkung beigemessen: In einem viel beachteten Vorlagebeschluss zum Bundesverfassungsgericht ließ der Bundesfinanzhof unlängst wissen, der Gesetzgeber hätte gegebenen-

1 Schon 1978 brachte der SPIEGEL einen ausführlichen Beitrag unter dem Titel »Das ist Betrug am Normalbürger« (Nr. 19/1978, S. 67 ff.). Vgl. statt vieler etwa für die wissenschaftliche Diskussion Anfang der 1980er Jahre Voigt, Editorial, in: Seibel, Die Nutzung verwaltungswissenschaftlicher Forschung für die Gesetzgebung. Chancen und Risiken weniger komplexer Rechtssetzungen, München 1984 und Seibel, a.a.O., 11 ff.. Die zunehmende Komplexität des Rechts scheint ein globales Phänomen zu sein, vgl. etwa Burton/Dirkis, Defining Legislative Complexity. A Case Study: The Tax Law Improvement Project, 14 U Tas L Rev 198 (1995); Green, Accounting Standards and Tax Law: Complexity Dynamism and Divergence, British Tax Review 1995, $445 \mathrm{ff}$; Ost/van de Kerchove, Constructing the Complexity of the Law: Towards a Dialectic Theory, in: Wintgens (Hg.), The Law in Philosophical Perspectives, Dordrecht u.a. 1999, 147 ff.; Schuck, Legal Complexity: Some Causes, Consequences, and Cures, 42 Duke L.J. 1, 9 ff. (1992).

2 Borell/Schemmel, Steuervereinfachung, DStZ 1987, 110 (110) führt den Begriff »Steuerdschungel« in die rechtswissenschaftliche Diskussion ein und hinterlegt diesen Begriff für die damalige Zeit mit erschütternden Zahlen zu Steuern, Steuergesetzen, Steueränderungsgesetzen, Durchführungsgesetzen und dergleichen. Vgl. des Weiteren statt vieler Weber-Grellet, Strukturwandel des Steuerstaats, DB 2007, 1717 ff.; Papier, Verfassungsrechtliche Grundlagen der Besteuerung, in: Brandt (Hg.), Für eine bessere Steuerrechtskultur. Erster Deutscher Finanzgerichtstag 2004, Stuttgart 2004.

3 Ein anschauliches aktuelles Beispiel bietet das europäische Chemikalienrecht mit der »REACH«Verordnung, EG 1907/2006, die mit der zu ihrer Auslegung erforderlichen, von der Kommission bzw. der einzusetzenden Agentur bspw. nach Art. 77 der Verordnung zu erstellenden »Leitlinien« mehrere tausend Seiten stark ist. — Bei der Erstellung von Plänen im Rahmen von Planfeststellungsverfahren ist es (jedenfalls) in Nordrhein-Westfalen mittlerweile üblich, dass die Kanzlei des Antragstellers den entsprechenden Plan inklusive Nebenbestimmungen »entwirft«, der dann von der Bezirksregierung nur mehr noch überprüft und dann unter eigenem Briefkopf bekannt gemacht wird. — Für die alte Rechtslage im Energierecht etwa Wolf, Die komplexe Energielandschaft macht eine Stromregulierungsbehörde notwendig, Wirtschaftsdienst 1999, $423 \mathrm{f}$..

4 Etwa Luttermann, Normenklarheit im Steuerrecht und »unbestimmte« Rechtsbegriffe?, FR 2007, 18 (20 und passim). In den USA hat die Komplexität des Bilanzrechts, begünstigt durch strukturelle Defizite im Wirtschaftsrecht, bekanntlich schon zu spektakulären Insolvenzen geführt (z.B. im Falle »Enron«).

5 Vgl. BVerfG, Beschl. v. 9. April 2003, 1 BvL 1/01 u. 1 BvR 1749/01, BVerfGE 108, 52 (75).

6 Karpen, Gesetzescheck (2005 - 2007): Empfehlungen zur Qualitätsverbesserung von Gesetzen, ZRP 2008, 97.

7 Vgl. Sendler, Rechtsstaat im Defizit?, in: Sendler/Redeker (Hg.), Recht — Gerechtigkeit — Rechtsstaat, Köln 2006, 103 (113), a.A. Weber-Grellet, Strukturwandel des Steuerstaats, DB 2007, 1717 (1717).

8 Daneben zur st. Rspr. Etwa: BVerfG, Urt. v. 23. Oktober 1951, 2 BvG 1/51, BVerfGE 1, 14 (16, 45 ff.); seither st. Rspr., etwa Urt. v. 27. Juli 2005, 1 BvR 668/04, BVerfGE 113, 348 ff.; Urt. v. 12. April 2005, 2 BvR 581/01, BVerfGE 112, 304 ff.; Beschl. v. 3. März 2004, 1 BvF 3/92, BVerfGE 110, 33 ff.; Beschl. v. 9. April 2003, 1 BvL 1/01, 1 BvR 1749/01, BVerfGE 108, 52 ff.; Urt. v. 19.3.2003, 2 BvL 9-12/98, BVerfGE 108, 1 ff. (m.w.N.); Beschl. v. 10. November 1988, 2 BvR 1057, 1226, 980/91, BVerfGE 99, 216 ff.; Beschl. v. 31. Mai 1988, 1 BvR 520/83, BVerfGE 78, 214 ff.; Beschl. v. 8. Januar 1981, 2 BvL 3,9/77, BVerfGE 56, 1 ff.; Beschl. v. 7. Juli 1971, 1 BvR 775/66, BVerfGE 31, 255 ff.. 
falls »im Interesse der Normenklarheit ein einfacheres Konzept entwickeln müssen «? 9 . Der folgende Beitrag will im Hinblick auf einen im Folgenden eingeführten, rechtsbezogenen Komplexitätsbegriff (dazu II.) den gegenwärtigen Stand der Dogmatik des Gebots der Normenklarheit skizzieren (III.), deren frappierende Widersprüche zur (Rechts-)Wirklichkeit, zu anderen Verfassungsprinzipien und $\mathrm{zu}$ nachbarwissenschaftlichen Erkenntnissen aufzeigen (IV.) und diese schließlich durch eine staatsrechtlich orientierte dogmatische Neukonturierung aufzulösen versuchen (V.). Und er will zeigen, dass - so richtig die zitierte Entscheidung des Bundesfinanzhofes im Ergebnis ist — dem Gesetzgeber von Verfassungs wegen keineswegs pauschal abverlangt wird, einfache und dem Normadressaten unmittelbar verständliche Konzepte zu entwickeln.

9 BFH, Beschl. v. 6. September 2006, XI R 26/04, juris, Abs. 49; Az. BVerfG: 2 BvL 59/06. Ähnlich Papier, Verfassungsrechtliche Grundlagen der Besteuerung, in: Brandt (Hg.), Für eine bessere Steuerrechtskultur, 25 (30), der davon spricht, dass der Gesetzgeber sich zur Selbstkontrolle zwingen sollte und dazu »sein Konzept zu Ende zu denken«. 


\section{Komplexität}

Zunächst soll erläutert werden, was im Folgenden als Komplexität bezeichnet wird, und in welchem Verhältnis Komplexität und Normenklarheit stehen. Während Komplexität ${ }^{10}$ zwar ein aus der Erfahrung des Alltags gemeinhin verständlicher Begriff ist, fällt es nicht leicht, ihn so prägnant zu definieren, dass ihm für Fragen des Rechts genügend Substanz abgewonnen werden kann. Bisweilen wird daher Komplexität als Anknüpfungspunkt für wissenschaftliche Betrachtungen rundheraus abgelehnt; in anderen Fällen wird eine Definition vermieden und sorglos mit einem als intuitiv ${ }^{11}$ begriffen vorausgesetzten, allenfalls mit anekdotischer Evidenz unterfütterten, Konzept gearbeitet. ${ }^{12}$ Hier soll ein erster Versuch unternommen werden, den Begriff rechtswissenschaftlich greifbar zu machen.

\section{Definition}

Vor diesem Hintergrund sollen hier jene Dimensionen aufgezeigt und veranschaulicht werden, die normative Regelungen - Gesetze - komplex werden lassen, ohne aber deren Verhältnis zueinander zu klären und sie zu operationalisieren. ${ }^{13}$ Diese Dimensionen seien als Dichte und Interdependenz bezeichnet. ${ }^{14}$ Dichte meint die Anzahl der zu berücksichtigenden normativen Informationen, also die Zahl der Tatbestandsvoraussetzungen und Rechtsfolgenanordnungen bzw. Wirkungen innerhalb einer positiven Rechtsnorm. So sind etwa voraussetzungsvolle, vorfragen- oder begriffsreiche Normen dicht im hiesigen Sinne. Ganz entscheidend wird das Recht daneben durch Interdependenzen zwischen verschiedenen Normen (externe Interdependenz) oder zwischen den Voraussetzungen und Wirkungen ein und derselben Norm (interne Interdependenz) komplex, wenn also Normen oder deren Fragmente sich aufeinander beziehen oder

10 Grundlegend Simon, The Architecture of Complexity, 106 Proc. Amer. Phil. Soc. 467 (1962).

11 Der Umgang mit dem Komplexitätsbegriff erinnert stark an die legendäre Aussage von Justice Potter Stewart auf die Frage, ob ein Film »pornographisch« sei: »I shall not today attempt further to define the kinds of material I understand to be embraced within that shorthand description; and perhaps I could never succeed in intelligibly doing so. But I know it when I see it [...]« (1 Jacobellis v. Ohio, 378 U.S. 184, 197 [1964]).

12 In der deutschen Literatur wird, soweit ersichtlich, Komplexität nur als untechnisch-deskriptiver Begriff verwendet, vgl. etwa die im Folgenden oft bemühte BFH-Entscheidung, Beschl. v. 6. September 2006, XI R 26/04, juris, Abs. 30, 50, 54, 61, 71. Für die etwas sensibilisiertere ausländische Diskussion sei statt vieler hier nur verwiesen auf Burton/Dirkis, Defining Legislative Complexity, 14 U Tas L Rev 198 (1995); Green, Accounting Standards and Tax Law, British Tax Review 1995, 445; Ruhl, Thinking of Environmental Law as a Complex Adaptive System: How to clean up the environment by making a mess of environmental law, 34 Hous. L. Rev. 935 (1997); Schuck, Legal Complexity, 42 Duke L.J. 1 (1992) (mit zahlreichen weiterführenden Nachweisen). Ähnliche Schwierigkeiten wie hier bestehen auch bei anderen verwandten Begriffen, etwa dem »Normwiderspruch«, vgl. Schröder, Von Lenkungssteuern und Eisenbahnkreuzungen, ZG 2007, 236 (240).

13 Damit wird freilich auch auf ein konkretes »Maß« für Komplexität verzichtet; für die im Folgenden dargelegte Hypothese ist dies aber auch nicht erforderlich.

14 Die hier angebotene Definition ist inspiriert von Schuck, Legal Complexity, 42 Duke L.J. 1 (1992), 3 f., der allerdings die Komplexität eines oder mehrerer Regelungssysteme aus der Warte seiner Gegenstände in den Blick nimmt und dadurch zu anderen Definitionsmerkmalen gelangt. Vgl. auch aus rechtstheoretischer Perspektive Luhmann, Ausdifferenzierung des Rechts. Beiträge zur Rechtssoziologie und Rechtstheorie, Frankfurt am Main 1999, 241 ff.. 
gegenseitig bedingen. ${ }^{15}$ Durch externe Interdependenzen erhöht sich die Anzahl der bei der Beantwortung einer Rechtsfrage zu beachtenden Normen; ${ }^{16}$ sie macht das, was als »Normendschungel ${ }^{17}$ oder $»$ Hyperlexie ${ }^{18}{ }^{8}$ bezeichnet wird, auch auf der Ebene der einzelnen Norm und bei der Beantwortung einer einzelnen Frage anhand dieser Norm spürbar. ${ }^{19}$ Interdependenzen sind deswegen besonders heikel, weil sie die Zahl der zu berücksichtigenden Elemente durch mehrfach gestufte Wechsel- und Rückwirkungen dramatisch ${ }^{20} \mathrm{zu}$ erhöhen vermögen, und das über überschaubare Regelungskomplexe hinweg. ${ }^{21}$ Sie können auch in unbestimmten Rechtsbegriffen und Ermessensnormen verborgen liegen, die eine systematische oder teleologische Berücksichtigung anderer Normen erfordern, so dass die fragliche Norm kontextabhängig mit einer unüberschaubaren Vielzahl anderer Normen interagieren kann. ${ }^{22}$ Einen besonderen Fall normativer Interdependenzen stellt die Polytelie dar: Werden im Rahmen von Normen mit einem Zweckprogramm ${ }^{23}$ mehrere, ggf. sich widersprechende Zwecke verfolgt, so erfordert dies eine mehrdimensionale Informationsbewertung. Für gewöhnlich wird das Problem dogmatisch mit den Mitteln der Abwägung und der praktischen Konkordanz oder theoretisch durch Rückgriff auf die Prinzipientheorie ${ }^{24}$ zu lösen versucht, was indessen nicht darüber hinwegtäuschen darf, dass für eine methodisch strenge, dogmatische Lösung (bislang) adäquates Werkzeug fehlt. ${ }^{25}$

15 Für einen Vorschlag, wie Interdependenzen operationalisiert werden können, vgl. Luhmann, Ausdifferenzierung des Rechts, 241 ff. (250, Fn. 23).

16 Vgl. BVerfG, Beschl. v. 3. März 2004, 1 BvF 3/92, BVerfGE 110, 33 (63 f.). — Von den in den ersten zwei Jahren der 16. Legislaturperiode erlassenen 698 formellen Gesetzen und Rechtsverordnungen verwenden 350 Verweisungstechniken und weisen damit externe Interdependenzen auf (Karpen, Empfehlungen zur Qualitätsverbesserung von Gesetzen, ZRP 2008, 97 (99)).

17 Vgl. Borell/Schemmel, Steuervereinfachung, DStZ 1987, 110 (110); oft auch »Normenflut«, vgl. etwa Herzog, Gesetzgebung und Einzelfallgerechtigkeit, NJW 1999, 25 (25). Eindrucksvolle aktuelle Zahlen finden sich bei Karpen, 40 Jahre Gesetzgebungslehre in Deutschland und der Beitrag der ZRP, ZRP 2007, 234 (235), demzufolge es allein auf Bundesebene rund 86.000 Einzelvorschriften gibt; die in der ersten Hälfte der laufenden 16. Legislaturperiode erlassenen Normen umfassen 6.250 Seiten im Bundesgesetzblatt (Karpen, Empfehlungen zur Qualitätsverbesserung von Gesetzen, ZRP 2008, 97).

18 Manning, Hyperlexis: Our National Disease, 71 Nw. U. L. Rev. 767 (1976-1977).

19 Größere Interdependenzen erschweren etwa dem Gesetzgeber bei Normsetzung und -änderung und Verwaltung und Gerichten bei Normanwendung bzw. deren Kontrolle ihre Aufgaben beträchtlich.

20 Die Interdependenzen verschiedener Norm können zur sog. »kombinatorischen Explosion« führen.

21 Vgl. etwa BVerfG, Beschl. v. 3. März 2004, 1 BvF 3/92, BVerfGE 110, 33 (63 f.)

22 Freilich lassen sich viele Gegenstände überhaupt nicht sinnvoll ohne unbestimmte Rechtsbegriffe auf Tatbestands- oder Ermessen auf Rechtsfolgenseite regeln.

Interessant ist in diesem Zusammenhang auch die Fragestellung, ob eine Norm eine »Rechtsregel« oder einen »Verhaltensstandard « etabliert (in der rechtsökonomischen Literatur firmiert diese Unterscheidung unter dem Schlagwort »rules versus standards«). Während eine Rechtsregel ein ex ante klar formuliertes Programm enthält, werden Verhaltensstandards (etwa Sorgfalts- und Treuepflichten) ex post und bezogen auf einen konkreten Einzelfall (in der Regel durch Gerichte) konkretisiert. Vgl. zu dieser Diskussion etwa Kaplow, Rules versus Standards: An Economic Analysis, 42 Duke L.J. 557 (1992); Diver, The Optimal Precision of Administrative Rules, 93 Yale L.J. 65 (1983); aus dem aktuellen deutschen Diskurs etwa Fleischer, Gesetz und Vertrag als alternative Problemlösungsmodelle im Gesellschaftsrecht, ZHR 168 (2004), 673.

23 Zur Unterscheidung von Konditional- und Zweckprogrammen überblicksartig einführend Röhl, ${ }^{2}$ Allgemeine Rechtslehre, Köln 2001, 217 ff.; grundlegend Luhmann, ${ }^{2}$ Das Recht der Gesellschaft, Frankfurt / M. 1997 , 195 ff.. Zu komplexen Verwaltungsentscheidungen theoretisch fundiert Hoppe, Gerichtliche Kontrolldichte bei komplexen Verwaltungsentscheidungen, in: Hoppe, Grundfragen des Planungsrechts. Ausgewählte Veröffentlichungen, Münster 1998, $224 \mathrm{ff..}$

24 Vgl. Alexy, ${ }^{3}$ Theorie der Grundrechte, Frankfurt am Main 1996, insbes. etwa $71 \mathrm{ff.}$.

25 Polytele Normen lassen sich zwar durch Gleichungen mit mehreren Variablen theoretisch abbilden und lösen; für die Rechtsdogmatik ist das aber wenig ertragreich, weil schon über die Interaktionseffekte zwischen den verschiedenen Zielen Unsicherheit besteht (und erst recht über die zu subsumierenden Fakten). 
Das erklärt letztlich auch die hohe Streitanfälligkeit polyteler Normen und den Umstand, dass oft genug aus derselben Norm mit gleicher Berechtigung gegensätzliche Ergebnisse gefolgert werden können. Erst Interdependenzen führen schließlich dazu, dass auf Bruchlosigkeit und Widerspruchsfreiheit zu achten ist, also auf Konsistenz ${ }^{26}$ innerhalb einer Norm (interne Konsistenz) und von verbundenen Normen (externe Konsistenz). Betrachtet man beide Kategorien — Dichte und Interdependenzen - im Zusammenhang, dann wird offenkundig, dass die Erhöhung der einen zu einer Reduktion der anderen und damit theoretisch insgesamt zu einer Reduktion der Komplexität führen kann. So kann beispielsweise eine Erhöhung der Normdichte bei gleichzeitiger Reduktion der Interdependenzen in Summe zu geringerer Komplexität führen: Man braucht dann nur beispielsweise noch die Norm zu finden, die auf den einen Spezialfall anzuwenden ist. Zur Veranschaulichung von Dichte und Interdependenzen mag die einfache Frage dienen, ob ein Bauherr einen Anspruch auf die Genehmigung eines bestimmten Vorhabens hat. Der landesrechtlichen Bauordnung zufolge ist die Baugenehmigung zu erteilen, wenn dem Vorhaben öffentlich-rechtliche Vorschriften nicht entgegenstehen (§ 75 Abs. 1 S. 1 BauO NRW, vgl. $§ 72$ Abs. $1 \mathrm{MBO}$ ). Die Dichte dieser Norm ist gering: Es gibt lediglich eine geschriebene Tatbestandsvoraussetzung und eine klare Rechtsfolge. Dagegen sind die Interdependenzen des Gesetzes enorm, denn es sind (scheinbar) alle Normen des öffentlichen Rechts in Bezug genommen. ${ }^{27}$ Sehr anschaulich werden die mit Interdependenzen verbundenen Schwierigkeiten auch bei Betrachtung des planungsrechtlichen Abwägungsgebots, bei dem gesetzlich angeordnet vielfältiges — tatsächliches wie rechtliches - Abwägungsmaterial zu berücksichtigen und zu bewerten ist. ${ }^{28}$ Schließlich ist zu bemerken, dass Dichte und Interdependenzen zur Komplexität in einem Verhältnis des »je-mehr-desto« stehen: Komplexität ist also keine dichotome (komplex/simpel), sondern eine graduelle (mehr/weniger komplex) Normeigenschaft.

\section{Wirkung}

Im hier verwendeten Sinne ist Komplexität außerdem ein objektives Maß, wie etwa CelsiusGrade für die Messung der Temperatur. Damit ist sie für sich genommen weder wünschenswert noch nachteilig, ${ }^{29}$ ganz so, wie nicht per se gesagt werden kann, ob hohe Temperaturen wün-

Zu Normwidersprüchen jüngst etwa Schröder, Von Lenkungssteuern und Eisenbahnkreuzungen, ZG 2007, 236.

$26 \mathrm{Zu}$ Inkonsistenzen im Recht und dazu, dass sie bisweilen sinnvoll sein können vgl. Engel, Inconsistency in the Law: In Search of a Balanced Norm, in: Engel/Daston (Hg.), Is there Value in Inconsistency?, BadenBaden 2006, 221 ff. (vgl. insbes. 250 ff.)

27 Hinzu kommt der Umstand, dass zumindest der Laie zunächst klären muss, was das »öffentliche Recht« ist. Besonders drastische Beispiele für eine durch Dichte und Interdependenzen erhöhte Rechtskomplexität, freilich für eine andere Zeit, referiert Wagener, Der öffentliche Dienst im Staat der Gegenwart, VVDStRL 37 (1978), 215 (246): »In Nordrhein-Westfalen stehen einer Baugenehmigung 38 Bundesgesetze, 42 Bundesverordnungen und 6 Bundesrichtlinien, 59 Landesgesetze und Verordnungen, 16 Richtlinien sowie 128 Erlasse entgegen.« Einzelheiten dieses Beispiels entstammen LT-Drs. NRW 8/3049; s. auch Fn. 17. Vgl. BVerfG, Beschl. v. 9. April 2003, 1 BvL 1/01 u. 1 BvR 1749/01, BVerfGE 108, 52 (75).

28 Grundlegend etwa Hoppe, Die »Zusammenstellung des Abwägungsmaterials« und die »Einstellung der Belange « in die Abwägung »nach Lage der Dinge« bei der Planung, in: Hoppe, Grundfragen des Planungsrechts, 200 ff.; ein sehr anschauliches Beispiel findet sich auf S. 209 f., der grundlegende Lösungsansatz auf S. $213 \mathrm{ff}$.

29 So auch Schuck, Legal Complexity, 42 Duke L.J. 1 (1992), 8. 
schenswert oder nachteilig sind. Es kann aber — im Folgenden sehr kursorisch geschildert — die Wirkung der Komplexität beobachtet und bewertet werden, dass sie nämlich das Verständnis und die Anwendbarkeit der Normen erschwert. ${ }^{30}$ Die Unsicherheit der Adressaten bei der Prognose der Regelwirkungen nimmt zu, und es wird für sie schwieriger, ihr Verhalten an der Norm auszurichten. Mit dem Vokabular der Kognitionswissenschaft ausgedrückt: Durch steigende Komplexität - sowohl bei einer starken Erhöhung der Dichte als auch der Interdependenzen wachsen auch die (kognitiven) Anforderungen für die Bewältigung des in der Norm niedergelegten Regelungsprogramms. Dies ist darauf zurückzuführen, dass das für die bewusste Verarbeitung von Informationen zuständige Arbeitsgedächtnis über eine kognitive Kapazitätsgrenze (Gedächtnisspanne) von $7( \pm 2)$ Informationseinheiten (chunks) verfügt. ${ }^{31}$ Zur Verarbeitung großer Informationsmengen werden unter Nutzung des Langzeitgedächtnisses größere Mengen von Informationen in komplexe Informationseinheiten »gepackt«. So könnten beispielsweise die vier Informationseinheiten 1, 9, 8, 9 unter Nutzung historischen Wissens als nur eine Informationseinheit abgespeichert werden. Diese Zusammenfassung von Informationen (chunking) sowie deren späteres »Entpacken« setzen zumindest Strukturierungswissen, meist aber sogar fachspezifisches Wissen voraus. Je höher die Dichte und die Interdependenz, desto mehr kognitive Kosten (Aufmerksamkeit) fallen für das Entpacken von Inhalten an. Dies verringert die verfügbare Aufmerksamkeit, die benötigt wird, um andere Inhalte im Gedächtnis zu halten. ${ }^{32}$ Somit verringern Dichte und Interdependenz die Anzahl der Informationseinheiten, die im Arbeitsgedächtnis gehalten werden können. Durch Übung und die Bildung von Expertise werden Menschen befähigt, ihre Chunking-Strategien zu optimieren, sie können somit mehr Informationen im Sinne größerer und komplexerer Informationseinheiten verarbeiten; ${ }^{33}$ auf solche Experten wird später noch zurückzukommen sein. Der Erwerb dieses Wissens ist freilich seinerseits mit kognitiven, zeitlichen und/oder monetären Kosten verbunden. ${ }^{34}$ Natürlich kann man sich auch anderer Hilfsmittel bedienen, um die kognitive Kapazitätsgrenze hinauszuschieben: Papier und Bleistift oder Computer sind die einfachsten denkbaren Instrumente, aber auch der Rückgriff auf den Rat von Experten (also auf die Expertise Anderer) oder die Delegation der Entscheidung an kollektive oder korporative Akteure sind oft beobachtete Strategien im Umgang mit Komplexität.

30 Das kann mannigfaltige Folgen haben: Die Transaktionskosten steigen aufgrund der durch die Komplexität ausgelösten Unsicherheit; die Verwaltung aufgrund komplexen Rechts wird teurer; der Gesetzgeber hat größere Schwierigkeiten, es zu formulieren und sich zu einigen; es wird schwerer, das einmal gesetzte Recht wieder zu ändern; usw. Vgl. Schuck, Legal Complexity, 42 Duke L.J. 1 (1992), 18 ff..

31 G. A. Miller, The magical number seven, plus or minus two: some limits on our capacity for processing information, Psychological Review, 63 (2), 81 - 97.

32 H. A. Simon, How big is a chunk?, Science 183 (4124), $482-488$.

33 Zum Ganzen: D. Reisberg, Cognition: Exploring the science of mind, New York 1997, insbes. S. 135 ff..

34 Diesen Kosten kann aber ein höherer gesellschaftlicher Wohlfahrtsgewinn gegenüberstehen, der dann eine Komplexitätssteigerung sinnvoll erscheinen lässt. Das verkennen Schröder/Würdemann, Verständlichere Gesetzessprache - Institutionalisierung der Sprachprüfung im Gesetzgebungsverfahren, ZRP 2007, 231 (231). Wie hier Schuck, Legal Complexity, 42 Duke L.J. 1 (1992), 8; vgl. auch Borell/Schemmel, Steuervereinfachung, DStZ 1987, 110 (112 u. 114). Dazu auch unten IV.3.b). 


\section{Perspektive}

Die Beurteilung der Komplexität ist vom jeweiligen Blickwinkel abhängig. Von konkreter Komplexität kann dann gesprochen werden, wenn man die Komplexität einer Norm vor dem Hintergrund einer bestimmten Fragestellung, eines konkreten Sachverhaltes betrachtet. Im Einzelfall etwa kann das abzuarbeitende Normprogramm verkürzt sein, weil einzelne normative Anknüpfungspunkte ausgeblendet werden können (wenn etwa ihre Beantwortung evident ist), und folglich nur ein Ausschnitt der Gesamtregelung in den Blick genommen wird. Dagegen lässt sich Komplexität auch abstrakt, vom Regelungsgehalt der Norm her, denken; dann betrachtet man die Norm »als solche« in all ihrer Dichte und mit allen Interdependenzen. Eine weitere Unterscheidung lässt sich anhand des Begriffspaars relativ/absolut erklären. Es liegt schon nach der geschilderten Wirkung der Komplexität einer Norm auf der Hand, dass deren Bewertung im Auge des Betrachters - etwa des Normgebers, des Normadressaten oder eines Rechtskundigen - liegt; in der Temperatur-Analogie wäre an die "gefühlte« Temperatur (etwa im Sinne des Windchill-Faktors oder des Humidex) zu denken. Während die Bewertung anhand eines als absolut verstandenen Komplexitätsmaßes eine vollständige Durchdringung des Systems »Recht« voraussetzt und hier daher nicht näher interessiert, kann sich die Bewertung der Komplexität relativ zum Standpunkt des Betrachters verändern. So sind beispielsweise manche Interdependenzen einer Norm überhaupt nur für einen Rechtskundigen sichtbar, der um die (Legal-)Definition eines Tatbestandsmerkmals in einer anderen Norm weiß. Umgekehrt wird es einem Laien in aller Regel relativ schwerer fallen, bei Betrachtung der konkreten Komplexität jene Normbestandteile auszumachen, die er bei der Beantwortung einer bestimmten Frage nicht näher zu untersuchen braucht.

\section{Reduktion}

Interessant für die Reduktion der Komplexität des Regelungsgehalts einer Norm sind Konzepte wie Hierarchie ${ }^{35}$ oder der aus Psychologie und Informatik bekannten Gestalt. ${ }^{36}$ Diese lassen uns im Recht beispielsweise einen Verwaltungsakt als solchen erkennen und nicht bloß die einzelnen Elemente einer hoheitlichen Maßnahme, die eine Behörde zur Regelung eines Einzelfalls auf dem Gebiet des öffentlichen Rechts trifft, und die auf unmittelbare Rechtswirkung nach außen gerichtet ist. ${ }^{37}$ Da andere Normen nun nur mehr an den Begriff des Verwaltungsaktes anknüpfen und nicht mehr an die einzelnen zugrundeliegenden Merkmale, werden Normdichte sowie Interdependenzen und damit die Komplexität reduziert. Rechtskundige erkennen bei konkreten

35 Simon, The Architecture of Complexity, 106 Proc. Amer. Phil. Soc. 467 (1962).

36 Aus verhaltenspsychologischer Sicht reduziert außerdem Vertrauen Komplexität kognitiv (was ein zusätzlicher Grund seines Schutzes auch durch das Recht ist), unter anderem dadurch, dass die durch Vertrauen »geklärten« Fragen kognitiv keiner weiteren Bearbeitung bedürfen. Das spielt auch bei der Vermittlung des Rechst durch Intermediäre eine Rolle, s.u. IV.3.d). Zum Verhältnis von Vertrauen und Rationalität ausführlich Lahno, Der Begriff des Vertrauens, Paderborn 2002, etwa 127ff., 397 ff., 420 ff., 425 ff.; vgl. Engel, Vertrauen - ein Versuch, Preprints of the Max Planck Institute for Research on Collective Goods 1999/12, 1999.

37 Das gilt darüber hinaus auch für Definitionen von Begriffen, die nicht positivrechtlich normiert sind. 
Fragen mit Hilfe der juristischen Begriffsbildung Rechtskonstruktionen (wie etwa den Verwaltungsakt) im Lebenssachverhalt wieder und können aufgrund ihres Wissens und ihrer Erfahrung darüber hinaus größere, im konkreten Einzelfall unerhebliche Teile der Norm »ausblenden«. Sie reduzieren damit dann die konkrete Komplexität. Juristische Dogmatik — insbesondere die Bildung von Begriffen und Kategorien — kann in diesem Sinne auch als wirksame Methode zur Reduktion relativer und konkreter Komplexität des Rechts verstanden werden. Das gilt wie erwähnt allerdings nur, wenn Wissen zur Verarbeitung des übergeordneten Begriffes vorhanden ist; andernfalls steigert dessen Einführung die relative Komplexität, weil er als gleichgeordneter Terminus scheinbar die Dichte erhöht. ${ }^{38}$ Dieses ambivalent anmutende Konzept, das besonderen technischen oder rechtlichen Sachverstand erforderlich macht, sei im Folgenden als Technizität bezeichnet. Besonderer technischer Sachverstand allein zum Verständnis der Norm ist etwa im Umwelt- und Technikrecht oder im Steuerrecht erforderlich; besonderer rechtlicher, wenn sich das Recht Instrumenten wie Regulierung oder Planfeststellung oder unbestimmter Rechtsbegriffe (»Zuverlässigkeit«, »Treu und Glauben«) bedient. ${ }^{39}$ Wichtig ist, dass die Technizität die absolute Komplexität des Rechts tatsächlich reduziert, vom nicht juristisch vorgebildeten Normadressaten aber als komplexitätssteigernd wahrgenommen wird. Hier kommt die oben eingeführte relative Perspektive auf Komplexität besonders zum Tragen. Und es lässt sich sagen, dass es zur Beherrschung der Komplexität im Allgemeinen zusätzlichen Wissens bedarf.

38 In diesem Zusammenhang sei auf die epochalen Erkenntnisse Piagets zur Klasseninklusion bei Kindern hingewiesen (vgl. etwa Montada, Die Geistige Entwicklung aus der Sicht Jean Piagets, in: Oerter/Montada (Hg.), ${ }^{4}$ Entwicklungspsychologie, Weinheim 1998, 518 (530 ff.)). Er hat gezeigt, dass kleine Kinder Probleme mit der Verwendung von Ober- und Unterbegriffen haben. So kannten Kinder die Begriffe »Kinder«, »Knaben« und »Mädchen«, betrachteten aber »Mädchen« als eigene Klasse und konnten nicht verinnerlichen, dass es sich um eine Klasse innerhalb der Klasse »Kinder« handelt. Während Piaget seine Erkenntnisse mit biologischen Beschränkungen erklärt, kann hier jedenfalls insofern eine Analogie festgestellt werden, als dem juristisch nicht vorgebildeten Rechtsanwender bei hierarchisch gebildeten Begriffen in aller Regel strukturell die Fähigkeit zur Klasseninklusion fehlen dürfte.

39 Es zeigt sich also, dass unbestimmte Rechtsbegriffe die Komplexität zwar steigern, aber gleichermaßen auch zu ihrer Reduktion eingesetzt werden können. 


\section{Normenklarheit}

Darüber hinaus kennt das Recht ein Instrumentarium, das seiner eigenen Reinhaltung dient. Hier geht es nicht um Komplexitätsreduktion, sondern um Komplexitätskontrolle. Das Gebot der Normenklarheit ist das Werkzeug, mit dem unter anderem zu komplexe Gesetze aussortiert werden. Es markiert also gleichsam die Ränder der Rechtmäßigkeit normativer Komplexität — geht aber auch darüber hinaus, wenn es andere pathologische (etwa perplexe ${ }^{40}$ ) Normen ausscheidet. Im Folgenden soll es allein um jenen Ausschnitt Normenklarheit gehen, aus dem sich das Verfassungswidrigkeitsverdikt für überkomplexe Normen ergibt. Bedeutsam ist, dass das Prinzip der Normenklarheit am Normtext und an Normzusammenhängen — also am positiven Recht — anknüpft, nicht aber an einer wie auch immer konstatierten Komplexität des Rechts schlechthin. ${ }^{41}$ Die dem Gebot der Normenklarheit nach gegenwärtiger Dogmatik zugrundeliegende Mechanik setzt bei der Verständlichkeit von Normen an: Wenn eine Norm unverständlich ist, dann kann ihre Befolgung nicht verlangt werden - ultra posse nemo tenetur. Der Befolgungsanspruch der Norm wird kassiert, indem sie für verfassungswidrig erklärt wird. Und die Verfassungswidrigkeit wird dogmatisch mit einem Verstoß gegen das verfassungsrechtliche Gebot der Normenklarheit begründet. Nun kann es eine ganze Reihe von Gründen geben, deretwegen eine Norm unverständlich ist. Hier interessieren in erster Linie die - in der verfassungsgerichtlichen Rechtsprechung wie wohl auch tatsächlich — wichtigsten Fälle: Jene Normen, die wegen der Komplexität ihrer Regelung schwer oder nicht verständlich sind.

Doch was meint Normenklarheit, und vor allem: anhand welchen Bezugspunktes wird sie beurteilt? Der im Wesentlichen von der Rechtsprechung geprägte, heute gebräuchliche Rechtsbegriff der Normenklarheit ist nur unscharf umrissen. Auf seine verfassungsrechtliche Herleitung (1.) wird kaum Mühe verwendet, der materielle Gehalt (2.) ist ebenso vielschichtig wie vage. Auch der Bezugspunkt (3.) - die Frage, auf wen bei der Bestimmung der Einhaltung des Gebots abzustellen ist - kann weder einheitlich noch nach klaren Kriterien bestimmt werden. ${ }^{42}$ Letztlich ist zu konstatieren, dass kein einheitliches Verständnis von den Inhalten und Zielen des Gebots der Normenklarheit besteht.

\section{Verfassungsrechtliche Herleitung}

Das Bundesverfassungsgericht ordnet das Erfordernis der Normenklarheit ohne weitere Begründung in starker Anlehnung an das Bestimmtheitsgebot dem Rechtsstaatsprinzip zu. ${ }^{43}$ Dem Kon-

40 Perplexe Normen sind nichtig, wenn sich die Perplexität nicht anderweitig auflösen lässt (etwa durch den Grundsatz lex specialis derogat legi generali). Zu Normwidersprüchen zuletzt etwa Schröder, Von Lenkungssteuern und Eisenbahnkreuzungen, ZG 2007, 236.

41 Zum Recht zählt nach hiesigem Verständnis des Begriffs mehr als nur der Normtext. Siehe dazu auch unten IV.3.a).

42 Vgl. Schnapp, in: v. Münch/Kunig, Grundgesetz, Bd. 2, 5. Auflage 2001, Art. 20, Rz. 64, 66 (zur Dogmatik von Art. $20 \mathrm{GG})$.

43 BVerfG, Urt. v. 23. Oktober 1951, 2 BvG 1/51, BVerfGE 1, 14 (45); Urt. v. 30. Mai 1956, 1 BvF 3/53, BVerfGE 5, 25 (31); Beschl. v. 12. Januar 1967, 1 BvR 169/63, BVerfGE 21, 73 (79); Beschl. v. 7. Juli 1971, 1 BvR 775/66, BVerfGE 31, 255 (264); Beschl. v. 12. Juni 1979, 1 BvL 19/76, BVerfGE 52, 1 (41); Beschl. 
text der im Hinblick auf die verfassungsrechtliche Begründung des Erfordernisses der Normenklarheit regelmäßig sehr knapp gehaltenen Entscheidungen kann bisweilen entnommen werden, dass dem die Vorstellung zugrunde liegt, nur klare und widerspruchsfreie Normen seien auch justitiabel. ${ }^{44}$ In Einzelfällen schimmern Anleihen am Demokratieprinzip und dem Grundsatz der Gewaltenteilung durch. ${ }^{45}$ Kunig stellte dann 1985 fest, es sei ein derartiger Verfestigungsgrad der Rechtsprechung zur Normenklarheit erreicht, dass es das Bundesverfassungsgericht »offenbar nur mehr für nötig hält, schlicht zu überprüfen, ob eine Norm die erforderliche Klarheit aufweist, « ohne das Gebot der Normenklarheit dabei ausdrücklich aus dem Rechtsstaatsprinzip herzuleiten oder gar überhaupt zu benennen. ${ }^{46}$ Die im Schrifttum vorherrschende Auffassung die sich oft genug in einer Zusammenstellung der bundesverfassungsgerichtlichen Rechtsprechung erschöpft ${ }^{47}$ — bewegt sich ganz auf dieser Linie und ordnet das Erfordernis inhaltlicher Klarheit von Rechtsnormen ebenfalls dem Rechtsstaatsprinzip zu, ${ }^{48}$ mit dem ergänzenden Hinweis, es sei Voraussetzung für die Rechtssicherheit, einem konstitutiven Merkmal des Rechtsstaates. $^{49}$

\section{Inhalt}

\section{a) Normen}

Soweit ersichtlich bisher nicht erörtert ist die Frage, auf welche Normen das Gebot der Normenklarheit Anwendung findet. Aus der verfassungsrechtlichen Fundierung lässt sich zu dieser Frage nichts sagen. Angesichts der bundesverfassungsgerichtlichen Kasuistik steht fest, dass jedenfalls Parlamentsgesetze klar gefasst sein müssen; das liegt freilich daran, dass allein für diese das Normverwerfungsmonopol beim Bundesverfassungsgericht liegt. Vor dem Hintergrund der

v. 24. November 1981, 2 BvL 4/80, BVerfGE 59, 104 (114); Beschl. v. 8. März 1983, 2 BvL 27/81, BVerfGE 63, 312 (323 f.); Beschl. v. 31. Mai 1988, 1 BvR 520/83, BVerfGE 78, 214 (226); Urt. v. 19.3.2003, 2 BvL 9-12/98, BVerfGE 108, 1 (20); Beschl. v. 3. März 2004, 1 BvF 3/92, BVerfGE 110, 33 (53); Urt. v. 27. Juli 2005, 1 BvR 668/04, BVerfGE 113, 348 (376). Vgl. auch BFH, Beschl. v. 6. September 2006, XI R 26/04, juris, Abs. 25. Papier/Möller, Das Bestimmtheitsgebot und seine Durchsetzung, AöR 122 (1997), 177 (184) sowie Sobota, Das Prinzip Rechtsstaat. Verfassungs- und verwaltungsrechtliche Aspekte, Habil., Tübingen 1997, 497 (Nr. 64 und 62 a.E.) unterscheiden nicht zwischen Bestimmtheitsgebot und Normenklarheit.

44 Vgl. etwa BVerfG, Beschl. v. 12. Januar 1967, 1 BvR 169/63, BVerfGE 21, 73 (79); Beschl. v. 7. Juli 1971, 1 BvR 775/66, BVerfGE 31, 255 (264): In beiden Beschlüssen werden Normklarheit und Justiziabilität sogar in unmittelbarem Zusammenhang aufgeführt. - Die Argumentation erinnert an den Satz der Logik ex contradictione sequitur quodlibet.

45 Etwa BVerfG, Beschl. v. 20. Oktober 1980, 1 BvR 640/80, BVerfGE 58, 257 (277 f.).

46 Kunig, Das Rechtsstaatsprinzip. Überlegungen zu seiner Bedeutung für das Verfassungsrecht der Bundesrepublik Deutschland, Tübingen 1986, 201.

47 Vgl. etwa Papier/Möller, Das Bestimmtheitsgebot und seine Durchsetzung, AöR 122 (1997), 177.

48 Etwa Sachs, in: Sachs (Hg.), Grundgesetz, 5. Auflage 2007, Art. 20, Rz. 123 ff.; Schulze-Fielitz, in: Dreier (Hg.), Grundgesetz, Band II, 2. Auflage 2006, Art. 20, Rz. 141 ff.; Jarass, in: Jarass/Pieroth, Grundgesetz, 9. Auflage 2007, Art. 20, Rz. 60 ff.; Sommermann, in: v. Mangoldt/Klein/Starck (Hg.), Grundgesetz, Band 2, 4. Auflage 2000, Art. 20, Rz. 278 ff.; Papier, Verfassungsrechtliche Grundlagen der Besteuerung, in: Brandt (Hg.), Für eine bessere Steuerrechtskultur, 25 (29).

49 Sachs, in: Sachs (Hg.), Grundgesetz, Art. 20, Rz. 123 ff.; Sommermann, in: v. Mangoldt/Klein/Starck (Hg.), Grundgesetz, Band 2, 4. Auflage 2000, Art. 20, Rz. 279 f.; Papier/Möller, Das Bestimmtheitsgebot und seine Durchsetzung, AöR 122 (1997), 177 (179). Einführend zum Grundsatz der Normenklarheit jüngst Grefrath, Der Grundsatz der Normenklarheit, JA 2008 (im Erscheinen). 
Verankerung des Gebots im Rechtsstaatsprinzip erscheint es sinnwidrig, Gesetze mit anderer demokratischer Legitimation — selbst wenn sie nach der Wesentlichkeitstheorie des Bundesverfassungsgerichtes keine wesentlichen Gegenstände regeln dürfen - auszunehmen. Auch einfache formelle und materielle Gesetze müssen demzufolge dem Gebot der Normenklarheit genügen.

\section{b) Klarheit}

Ganz grundsätzlich müssen gesetzliche Regelungen so gefasst sein, dass der Adressat »seine Normunterworfenheit und die Rechtslage so konkret erkennen kann, dass er sein Verhalten danach auszurichten vermag, $"{ }^{50}$ wenn auch nach Auslegung der Norm. ${ }^{51}$ Denn: »Was nicht verständlich ist, kann weder auf Verständnis hoffen noch auf Befolgung. « ${ }^{52}$ Das Gebot der Klarheit umfasst also die Vorfragen, die (Tatbestands-)Voraussetzungen und die Rechtsfolgen einer Norm. Soweit die praktische Bedeutung einer Regelung für den Normunterworfenen nicht von einer einzelnen Vorschrift abhängt, sondern vom Zusammenspiel von Normen unterschiedlicher Regelungsbereiche, müssen die Klarheit des Norminhalts und die Voraussehbarkeit der Ergebnisse der Normanwendung gerade auch im Hinblick auf dieses Zusammenwirken gesichert sein. ${ }^{53}$ Oft spielen dabei die als Unterbegriffe gedachten Termini »Bestimmtheit« und »Verständlichkeit« eine Rolle, die jedoch keine weitere Erläuterung erfahren und daher auch nicht zu einer weiteren Enthüllung der Klarheitsanforderungen beitragen; ${ }^{54}$ bei der Lektüre der Literatur zur Normenklarheit kommt man nicht umhin festzustellen, dass kein einheitliches Verständnis vom materiellen Gehalt herrscht.

Der Rechtsprechung ist ferner zu entnehmen, ein Gesetz müsse »sprachlich verständlich«, »insbesondere ohne innere Widersprüche $\ll^{55}$ (interne Konsistenz), »nicht fehleranfällig ${ }^{56}{ }^{56}$ und $»$ redaktionell genau ${ }^{57}$, sowie systematisch aufgebaut sein. ${ }^{58}$ Ferner dürfe es nicht in ein Umfeld

50 BVerfG Beschl. v. 9. April 2003, 1 BvL 1/01 u. 1 BvR 1749/01, BVerfGE 108, 52 (75); Beschl. v. 27. November 1990, 1 BvR 402/87, BVerfGE 83, 130 (145); Beschl. v. 3. November 1982, 1 BvR 210/79, BVerfGE 62, 169 (183); Beschl. v. 20. Oktober 1980, 1 BvR 640/80, BVerfGE 58, 257 (278); Beschl. v. 22. Juni 1977, 1 BvR 799/76, BVerfGE 45, 400 (420); Beschl. v. 12. Januar 1967, 1 BvR 169/63, BVerfGE 21, 73 (79). So auch die Literatur, vgl. etwa Benda, Die Wahrung verfassungsrechtlicher Grundsätze im Steuerrecht, DStZ 1984, 159 (insbes. 162).

51 BVerfG, Beschl. v. 22. Juni 1977, 1 BvR 799/76, BVerfGE 45, 400 (420); Beschl. v. 20. Oktober 1980, 1 BvR 640/80, BVerfGE 58, 257 (277 f.).

52 Herzog, Gesetzgebung und Einzelfallgerechtigkeit, NJW 1999, 25 (25 a.E.).

53 BVerfG Beschl. v. 9. April 2003, 1 BvL 1/01 u. 1 BvR 1749/01, BVerfGE 108, 52 (75); so auch Papier, Verfassungsrechtliche Grundlagen der Besteuerung, in: Brandt (Hg.), Für eine bessere Steuerrechtskultur, 25 (29).

54 Vgl. Grefrath, Der Grundsatz der Normenklarheit in der Fallbearbeitung, JA 2008 (im Erscheinen), m.w.N., der auch darauf hinweist, dass Verständlichkeit und Bestimmtheit oft gegenläufige Prinzipien sind, zur Auflösung des Konflikts aber nirgends Stellung bezogen wird; die Unterscheidung von Verständlichkeit und Bestimmtheit findet sich auch bei Choi, Die Pflicht des Gesetzgebers zur Beseitigung von Gesetzesmängeln, Diss., Hamburg 2002, http://deposit.ddb.de/cgi-bin/dokserv?idn=964408937 (abgerufen am 1.2.2008), 42, 48. Papier/Möller, Das Bestimmtheitsgebot und seine Durchsetzung, AöR 122 (1997), 177 (181) sprechen gar von »Klarheit, Bestimmtheit, Verständlichkeit und Praktikabilität«, ohne die Begriffe weiter gegeneinander abzugrenzen.

55 Vgl. etwa BVerfG, Urt. v. 15. Juli 2003, 2 BvF 6/98, BVerfGE 108, 169 (181).

56 Vgl. BVerfG, Beschl. v. 3. März 2004, 1 BvF 3/92, BVerfGE 110, 33 (64).

57 Vgl. etwa BVerfG, Beschl. v. 13. September 2005, 2BvF 2/03, BVerfGE 114, 196 (236). 
von rechtssystematischen Brüchen (externe Konsistenz) eingebettet sein, das den intellektuellen Zugang zur gesetzlichen Regelung erschwere. ${ }^{59}$ Diese Begriffe erfahren eine hilfreiche semantische Konkretisierung wenn das Gericht weiter ausführt, dass »eine gehäufte Verwendung sprachlich kaum abgrenzbarer unbestimmter Rechtsbegriffe [Interdependenzen, Technizität], eine umfangreiche Textlänge [Dichte], ein unübersichtlicher Gesetzesaufbau« ebenso wie »eine Häufung und Stufung von Regel-Ausnahme-Techniken, Mehrfachverweisungen und widersprüchliche Rechtsfolgenanordnungen [Interdependenzen, Technizität]« »sämtliche Merkmale einer dem Gebot der Klarheit widersprechenden Norm « seien. ${ }^{60}$

\section{c) Relativierung}

Der Rechtsprechung des Bundesverfassungsgerichts zufolge richten sich die Erfordernisse im Einzelfall nach Art und Schwere des jeweiligen Eingriffs in die Grundrechte, ${ }^{61}$ das heißt die Anforderungen an Klarheit und Bestimmtheit der Norm sind nach gängiger Dogmatik strenger, je stärker die Unsicherheit bei der Beurteilung der Gesetzeslage es dem Normadressaten erschwert, Grundrechte auszuüben. ${ }^{62}$ Die Orientierung an der Schwere des »Eingriffs« könnte dazu verleiten, das Gebot der Normenklarheit nur auf solche Vorschriften anzuwenden, die der Eingriffsverwaltung zuzurechnen sind; ${ }^{63}$ das Bundesverfassungsgericht stellt indessen ausdrücklich klar, dass das Erfordernis »auch bei der Gewährung von Leistungen und deren zivilrechtlicher Behandlung « gilt. ${ }^{64}$ Inwiefern das Gebot der Normenklarheit darüber hinaus etwa auch für die dispositiven Regelungen des Bürgerlichen Rechts gilt, bleibt offen.

Schließlich gewährt das Bundesverfassungsgericht dem Gesetzgeber noch eine weitere Erleichterung vom Gebot der Normenklarheit: Dieser hat Normen (lediglich) so genau zu fassen, »wie dies nach der Eigenart der zu ordnenden Lebenssachverhalte und mit Rücksicht auf den Normzweck möglich ist «. ${ }^{65}$ Was »möglich« ist, bleibt freilich offen: genügt jede Möglichkeit, handelt es sich um eine besondere Form der Erforderlichkeitsprüfung oder am Ende allein um eine Frage der Zweckmäßigkeit? Da hilft die Aussage, geringere Anforderungen seien vor allem bei der Regelung von »vielgestaltigen Sachverhalten ${ }^{66}{ }^{z u}$ stellen oder wenn die tatsächlichen

58 BFH, Beschl. v. 6. September 2006, XI R 26/04, juris, Abs. 50, 52 ff..

59 BFH, Beschl. v. 6. September 2006, XI R 26/04, juris, Abs. 62.

60 BFH, Beschl. v. 6. September 2006, XI R 26/04, juris, Abs. 54. Ähnlich auch schon Benda, Die Wahrung verfassungsrechtlicher Grundsätze im Steuerrecht, DStZ 1984, 159 (162).

61 Etwa BVerfG, Beschl. v. 20. Oktober 1980, 1 BvR 640/80, BVerfGE 58, 257 (277 f.).

62 Etwa BVerfG, Beschl. v. 3. März 2004, 1 BvF 3/92, BVerfGE 110, 33 (53 ff.); Beschl. v. 9. April 2003, 1 BvL 1/01 u. 1 BvR 1749/01, BVerfGE 108, 52 (75); Urt. v. 19. März 2003, 2 BvL 9-12/98, BVerfGE 108, 1 (20); Beschl. v. 20. Oktober 1980, 1 BvR 640/80, BVerfGE 58, 257 (278); Beschl. v. 19. April 1978, 2 BvL 2/75, BVerfGE 48, 210 (222 f.). So auch BFH, Beschl. v. 6. September 2006, XI R 26/04, juris, Abs. 25 , 28.

63 So lässt sich etwa auch der BFH lesen, vgl. BFH, Beschl. v. 6. September 2006, XI R 26/04, juris, Abs. 28.

64 Für das Kindergeld-, Unterhalts-, Steuer- und Sozialhilferecht BVerfG, Beschl. v. 9. April 2003, 1 BvL 1/01 u. 1 BvR 1749/01, BVerfGE 108, 52 (75).

65 Erstmalig BVerfG, Beschl. v. 26. September 1978, 1 BvR 525/77, BVerfGE 49, 168 (181).

66 Etwa Beschl. v. 20. Oktober 1980, 1 BvR 640/80, BVerfGE 58, 257 (278); Beschl. v. 15. April 1970, 2 BvR 396/69, BVerfGE 28, 175 (183); Beschl. v. 22. Juni 1960, 2 BvR 125/60, BVerfGE 11, 234 (237); Beschl. v. 30. November 1955, 1 BvL 120/53, BVerfGE 4, 352 (357 f.). 
Verhältnisse stetigem und schnellem Wandel unterliegen ${ }^{67}$ ebenso wenig wie jene, dass komplexe Sachverhaltsgestaltungen »spiegelbildlich« eine »vergleichbar komplexe Gesetzesantwort« rechtfertigen können. ${ }^{68}$ Unklar — wenn auch sehr nah an der oben postulierten Definition der Komplexität — bleibt auch die Formulierung des Bundesfinanzhofs, dass der »Anspruch des Normadressaten an die Informationsfunktion der Norm [sic!] größer wird je mehr Begriffe zur Beschreibung der Regelung nötig werden [Dichte], je komplexer die Begriffe sind [Technizität] und je mehr Verknüpfungen zwischen ihnen bestehen [Interdependenz]. « ${ }^{69}$

\section{Bezugspunkt}

Schließlich ist allgemein anerkannt, dass sich die Bewertung der Klarheit einer Norm und ihrer Wirkungen am Verständnis der Adressaten orientieren muss. ${ }^{70}$ Wenn der Adressat den Normbefehl nicht versteht, kann er ihn auch nicht befolgen. Das wird von der geschilderten verfassungsrechtlichen Fundierung des Gebots der Normenklarheit gestützt, denn wenn dieses dem Rechtsstaatsprinzip zu dienen bestimmt ist und Rechtssicherheit (das heißt insbesondere Vorhersehbarkeit $^{71}$ ) sicherstellen soll, dann muss die Norm — so das Bundesverfassungsgericht derart beschaffen sein, dass der Adressat »seine Normunterworfenheit und die Rechtslage so konkret erkennen kann, dass er sein Verhalten danach auszurichten vermag «. ${ }^{72}$ Im Steuerrecht soll das dem Bundesfinanzhof zufolge sogar bedeuten, dass der Steuerpflichtige »grundsätzlich anhand des ihm zugehenden Steuerbescheids seine Rechtmäßigkeit beurteilen können « ${ }^{73}$ muss. Anders als etwa in der strafrechtlichen Irrtumslehre wird dabei nicht auf die individuellen Fähigkeiten des Normadressaten abgestellt (denn gegenständlich ist die Klarheit einer abstraktgenerellen Regelung, kein konkreter Vorwurf gegen eine individuelle Person), sondern gleichsam auf die eines normativ normalisierten Betroffenen. ${ }^{74}$ Der Bundesfinanzhof spricht von der

67 BVerfG, Beschl. v. 12. November 1958, 2 BvL 4,26,40/56 u. 1,7/57, BVerfGE 8, 274 (326).

68 Obiter dictum des BFH für den Fall der »Abwehr sog. Abschreibungsmodelle o. Ä.«, Beschl. v. 6. September 2006, XI R 26/04, juris, Abs. 30; vgl. Herzog, Gesetzgebung und Einzelfallgerechtigkeit, NJW 1999, 25 (25).

69 BFH, Beschl. v. 6. September 2006, XI R 26/04, juris, Abs. 50.

70 St. Rspr., etwa BVerfG, Urt. v. 23. Oktober 1951, 2 BvG 1/51, BVerfGE 1, 14; Beschl. v. 12. Januar 1967, 1 BvR 169/63, BVerfGE 21, 73; Beschl. v. 12. Juni 1979, 1 BvL 19/76, BVerfGE 52, 1; Beschl. v. 8. März 1983, 2 BvL 27/81, BVerfGE 63, 312; Urt. v. 19.3.2003, 2 BvL 9-12/98, BVerfGE 108, 1; BFH, Beschl. v. 6. September 2006, XI R 26/04, juris, Abs. 41 ff.. Aus der h.M. in der Literatur statt vieler Herzog, Gesetzgebung und Einzelfallgerechtigkeit, NJW 1999, 25 (25); Papier/Möller, Das Bestimmtheitsgebot und seine Durchsetzung, AöR 122 (1997), 177 (184); mit Einschränkungen auch Choi, Die Pflicht zur Beseitigung von Gesetzesmängeln, 42 ff. (alle m.w.N).

71 Vgl. Sendler, Rechtsstaat im Defizit?, in: Sendler/Redeker (Hg.), Recht — Gerechtigkeit — Rechtsstaat, 103 (118 f.) und Kreppel, Persönlichkeitsrecht und Abgabepflicht. Das Tatbestandsmäßigkeitsprinzip und die Gestaltungsfreiheit des Steuergesetzgebers, in Schwarze/Graf Vitzthum (Hg.), Grundrechtsschutz im nationalen und internationalen Recht, Baden-Baden 1983, $119 \mathrm{ff..}$

72 St. Rspr.; BVerfG Beschl. v. 9. April 2003, 1 BvL 1/01 u. 1 BvR 1749/01, BVerfGE 108, 52 (75); Beschl. v. 27. November 1990, 1 BvR 402/87, BVerfGE 83, 130 (145); Beschl. v. 3. November 1982, 1 BvR 210/79, BVerfGE 62, 169 (183); Beschl. v. 20. Oktober 1980, 1 BvR 640/80, BVerfGE 58, 257 (278); Beschl. v. 22. Juni 1977, 1 BvR 799/76, BVerfGE 45, 400 (420); Beschl. v. 12. Januar 1967, 1 BvR 169/63, BVerfGE 21, 73 (79).

73 BFH, Beschl. v. 6. September 2006, XI R 26/04, juris, Abs. 43.

74 Vgl. Böhm, Der Normmensch. Materielle und prozedurale Aspekte des Schutzes der menschlichen Gesundheit vor Umweltschadstoffen, Tübingen 1996, $\S 3-6$ passim und $\S 9$. 
»objektivierten Sicht der Steuerpflichtigen ${ }^{75}{ }^{75}$ Das schließt gleichzeitig aus, dass auf Intermediäre $^{76}$, die dem Adressaten das Recht vermitteln können, als Bezugspunkt abgestellt wird. ${ }^{77}$

In einem gewissen Widerspruch dazu steht die Entscheidung des Bundesverfassungsgerichts, dass ein Gesetz dem Gebot der Normenklarheit genüge, wenn Probleme der Auslegung »mit herkömmlichen juristischen Methoden bewältigt werden können « ${ }^{78}$, denn selbst diese dürften dem juristischen Laien regelmäßig nicht geläufig sein. Ausnahmsweise, wenn der Normadressat »typischerweise « beraten ist, will der Bundesfinanzhof es auch genügen lassen, wenn der Inhalt des Gesetzes »dem Fachmann unter Aufbietung aller juristischen Interpretationsmöglichkeiten irgendwie [!] verständlich « ist. ${ }^{79} »$ Typischerweise « meint der Logik der Entscheidung nach dabei alle potenziellen Normadressaten (vulgo: alle Steuerzahler), so dass beispielsweise im Steuerrecht nicht davon ausgegangen werden kann, dass diese beraten sind, und zwar selbst dann nicht, wenn es um Normen geht, die in aller Regel gerade nicht alle Steuerpflichtigen betreffen. Freilich eröffnet diese Differenzierung die Möglichkeit, Gesetze in gewissen Bereichen großzügigeren Klarheits-Maßstäben zu unterwerfen, auch wenn sie sich als abstrakt-generelle Normen theoretisch an jedermann wenden. Erneut zeigt sich, dass beim gegenwärtigen Stand der Dogmatik zwar im Einzelfall plausible Entscheidungen zustande kommen, dass diese aber nicht von der Dogmatik geleitet sind, sondern in einem weite Spielräume gewährenden Bereich von klugen Richtern plausibel begründet werden.

75 BFH, Beschl. v. 6. September 2006, XI R 26/04, juris, Abs. 42.

76 Etwa Rechtsanwälte, Notare, Steuerberater, Verbände, aber auch Gerichte und die Verwaltung, schließlich insbesondere in Bereichen, die z.B. spezifischen technischen Sachverstand erfordern auch Techniker (z.B. Patentanwälte, Ingenieure, Architekten usw.). Zu den Intermediären wird man mit Inkrafttreten des RDG am 1.7.2008 wohl auch all jene zählen dürfen, die (eingeschränkte) außergerichtliche Rechtsberatung leisten dürfen. So etwa BVerfG, Beschl. v. 3. März 2004, 1 BvF 3/92, BVerfGE 110, 33 (64) und BFH, Beschl. v. 6. September 2006, XI R 26/04, juris, Abs. 45, hinsichtlich der Verwaltung mit unklarem Verweis auf BVerfG, Beschl. v. 31. Mai 1988, 1 BvR 520/83, BVerfGE 78, 214 (216).

78 BVerfG, Beschl. v. 27. November 1990, 1 BvR 402/87, BVerfGE 83, 130 (145).

79 BFH, Beschl. v. 6. September 2006, XI R 26/04, juris, Abs. 43; allerdings im Widerspruch zu BVerfG, Beschl. v. 3. März 2004, 1 BvF 3/92, BVerfGE 110, 33 (64). — Das erinnert an ein Bonmot des Österreichischen Verfassungsgerichts: »Es scheint aber, dass nur mit subtiler Sachkenntnis, außerordentlichen methodischen Fähigkeiten und einer gewissen Lust zum Lösen von Denksport-Aufgaben überhaupt verstanden werden kann, welche Anordnungen hier getroffen werden.« (http://www.ris.bka.gv.at/taweb-cgi/taweb? $\mathrm{x}=\mathrm{d} \& \mathrm{o}=\mathrm{d} \& \mathrm{v}=\mathrm{vfgh} \& \mathrm{~d}=\mathrm{VfGHT} \& \mathrm{i}=4573$, abgerufen am 1 . Oktober 2007). 


\section{Kritik}

Das Gebot der Normenklarheit in seiner aktuellen Ausprägung, insbesondere mit der Kalibrierung des tolerablen Maßes an Komplexität am Normadressaten, ist dogmatisch auf eine strikte Begrenzung der Komplexität von Normtexten und Normzusammenhängen gerichtet. Bisweilen kann man sich des Eindrucks nicht erwehren, dass es als rechtspolitisches Schwert nicht zur Kontrolle, sondern zur Reduktion von Komplexität missbraucht wird. Dabei werden wichtige Dimensionen des Rechts außer Acht gelassen.

\section{Verfassungsrechtliche Herleitung}

Dass es ein Gebot der Normenklarheit gibt, daran besteht kein Zweifel; aber es stellt sich die Frage, wo dieses Prinzip in der Verfassung verankert ist und welche Aussagen aus dieser Verankerung für dessen Gehalt abgeleitet werden können. Die Rückführung des Gebots der Normenklarheit auf das Rechtsstaatsprinzip dient dem erstgenannten Zweck: Sie verschafft dem Gebot eine plausible verfassungsrechtliche Grundlage. Materielle Aussagen lassen sich aus dieser Herleitung indessen nicht treffen, dafür ist ihr bloßer Verweis auf das Rechtsstaatsprinzip zu vage und knapp. ${ }^{80}$ So haben beispielsweise schon früh vereinzelte Stimmen in der Literatur darauf hingewiesen, dass die fehlende Normenklarheit nicht schlechthin eine Verletzung des Rechtsstaatsprinzips darstelle: ${ }^{81}$ Vielmehr sei ein solcher Verfassungsverstoß nur dann anzunehmen, wenn es einer Norm derart an Klarheit mangele, dass sie nicht mehr vollziehbar sei, denn durch den Erlass eines unklaren Gesetzes erbringe der Gesetzgeber »nur eine unvollkommene Leistung. Klarheit und Bestimmtheit sind Güteeigenschaften; fehlen sie, dann ist das Gesetz schlecht. $\ll^{82}$

Die wenig aussagekräftige und lieblose Herleitung des Erfordernisses klarer Normen in Rechtsprechung und Literatur dürfte dem Umstand geschuldet sein, dass über den plausiblen Gehalt des richterrechtlich entwickelten Gebotes Eintracht herrscht und Kontroversen, die eine Begründung des eigenen Standpunktes mit textlichen Belegen, Verfassungsprinzipien und dogmatischen Argumenten erfordert hätten, vergebens gesucht werden. Auch mag es von besonderer dogmatischer Ästhetik zeugen, wenn gerade das klare Normen fordernde Gebot selbst in strahlender Klarheit erscheint. Doch dieser Schein trügt. Der materielle Gehalt des Gebots der

80 Das liegt vor allem daran, dass dem Rechtstaatsprinzip ein sehr unterschiedlicher konkreter Bedeutungsgehalt beigemessen wird, so dass der bloße Rekurs auf das Prinzip unklar bleiben muss. Vgl. dazu etwa die von der Systematisierung der Inhalte des Prinzips bei Papier/Möller, Das Bestimmtheitsgebot und seine Durchsetzung, AöR 122 (1997), 177 (179), die auf 17 Kategorien verteilten 142 Merkmale bei Sobota, Das Prinzip Rechtsstaat, 471 ff. und Kunig, Das Rechtsstaatsprinzip, 201, demzufolge »das Rechtsstaatsprinzip« in aller Regel — so auch bei der Begründung des Gebots der Normenklarheit — keinen nennenswerten eigenen Bedeutungsgehalt aufweise und der Rückgriff darauf nur affirmativen Charakter habe.

81 Goeckel, Die Grundsätze des Rechtsstaates in der höchstrichterlichen Rechtsprechung der Bundesrepublik Deutschland, Diss., Tübingen 1965, 53 ff..

82 Goeckel, Die Grundsätze des Rechtsstaats, 55. Zu schlechten Gesetzen auch Sendler, Rechtsstaat im Defizit?, in: Sendler/Redeker (Hg.), Recht — Gerechtigkeit — Rechtsstaat, 103 (115, 116 f.); zu einer etwaigen Pflicht des Gesetzgebers zur Verbesserung schlechten Rechts vgl. Choi, Die Pflicht zur Beseitigung von Gesetzesmängeln,. 
Normenklarheit kann nämlich nur intuitiv erfasst und enumerativ beschrieben werden, weil die verfassungsrechtliche Verankerung für seine Konturierung mehr nicht hergibt. Entsprechend vielgestaltig sind die Versuche, den Inhalt des Gebots der Normenklarheit zu bestimmen. ${ }^{83}$

\section{Inhalt}

Und so verwundert es nicht, dass sowohl Rechtsprechung als auch juristisches Schrifttum die Anforderungen, die Normen für die Attestierung genügender Klarheit zu erfüllen haben, bisher vor allem durch zwar unmittelbar einleuchtende, aber doch sehr vage Begriffe zu objektivieren suchen. ${ }^{84}$ Fest steht allein, dass ein dem Gebot der Normenklarheit nicht genügendes Gesetz verfassungswidrig und damit nichtig ist. Trotz der klärenden Beispiele bleiben Fragen offen: Enthält eine polytele Norm schon einen inneren Widerspruch, wenn etwa das EnWG in $\S 1$ bestimmt, dass gleichwertige Gesetzeszwecke unter anderem die sichere, preisgünstige und umweltverträgliche Versorgung der Allgemeinheit mit Elektrizität und Gas sind? Warum darf eine Norm nicht fehleranfällig, warum muss sie redaktionell genau und systematisch aufgebaut sein? Wie werden Fehleranfälligkeit, redaktionelle Genauigkeit und systematischer Aufbau beurteilt? Dies alles sind, wie erwähnt, Qualitätsmerkmale, ohne die ein Gesetz zweifelsfrei schlecht ist — aber rechtfertigen sie pauschal das Verdikt der Verfassungswidrigkeit? Schließlich verwässert die Abhängigkeit des Klarheitsgebots von der Eingriffsintensität und der »Eigenart« der Lebenssachverhalte die Regeln seiner Anwendung. Wie die Eigenart eines Lebenssachverhalts oder die Erschwernis der Ausübung von Grundrechten zu bemessen wären, dafür gibt die Dogmatik nämlich keine Anhaltspunkte. Und was eine »mehr« oder »weniger« klare Norm ist, kann allenfalls sehr grob anhand objektiver Maßstäbe beurteilt werden, dürfte vielmehr sogar subjektiv je nach kognitiven oder sprachlichen Fähigkeiten oder der jeweiligen Präferenzordnung unterschiedlich sein. Unklar bleibt außerdem, ob bzw. wann sich der Bundesfinanzhof bei der Überprüfung der von ihm aufgestellten Kriterien auf die Komplexität der Regelung (den materiellen Gehalt) oder auf die Verständlichkeit der sprachlichen Darstellung (die formelle Darbietung) bezieht. ${ }^{85}$ Dies obwohl häufig zu beobachten ist, dass eine für sich genommen hinreichend verständliche Regelung sprachlich dermaßen ungeschickt ausgedrückt wird, dass sie — jedenfalls subjektiv — zu höherer Komplexität führt, und umgekehrt manch komplexe Regelung sprachlich äußerst klar ist. Die Überzeugungskraft des gefundenen Ergebnisses ist schlussendlich allein von Autorität und Rhetorik abhängig.

\section{Bezugspunkt}

Bar jeglicher Überzeugungskraft erweist sich bei genauer Betrachtung schließlich der dogmatische Bezugspunkt des Gebots der Normenklarheit. Die Orientierung am Normverständnis eines

83 Vgl. etwa die Einführung von Grefrath, Der Grundsatz der Normenklarheit, JA 2008 (im Erscheinen).

84 Dazu eingehend oben III.2.b).

85 Dasselbe Problem zeigt sich auch in der Literatur zur Normenklarheit, vgl. etwa Benda, Die Wahrung verfassungsrechtlicher Grundsätze im Steuerrecht, DStZ 1984, 159 (162). 
objektivierten Adressaten ignoriert die tatsächlich zu beobachtende Gesetzeskenntnis in der Gesellschaft (dazu a)) ferner nachbarwissenschaftliche Einsichten im Hinblick auf die Wirkungsweise (dazu b)) und die Kosten der Komplexität des Rechts (dazu c)). Aus verhaltenswissenschaftlicher Sicht ergibt sich ein uneinheitliches Bild (d)), während eine dogmatische Perspektive erhebliche Zweifel an der »Objektivierung« der Adressatensicht aufkommen lässt (e)). Diese Erkenntnisse haben an anderer Stelle im Recht bereits Niederschlag gefunden (f)).

\section{a) Realität: Gesetzeskenntnis und Rechtsverständnis der Bürger}

Der gemeine Normadressat hat für gewöhnlich zwar eine diffuse Kenntnis des Rechts, nicht aber eine konkrete des Gesetzes. ${ }^{86}$ Kein Bürger liest zu privaten Zwecken die Gesetzesblätter. ${ }^{87}$ Oft ist das Gesetz für ihn auch — tatsächlich ${ }^{88}$ wie sprachlich — überhaupt nicht zugänglich. Selbst die oft als neuzeitliche Ausrufer gehandelten Massenmedien vermitteln keine Gesetzes-, sondern

86 Für die Unterscheidung zwischen Gesetz und Recht sei auf die Rechtsprechung des Bundesverfassungsgerichts zu Art. 20 Abs. 3 GG verwiesen, etwa Beschl. v. 14. Februar 1973, 1 Bv 112/6 — ,Soraya', BVerfGE 34, 269 (286 ff.), dort mit Nachweisen: »Die traditionelle Bindung des Richters an das Gesetz, ein tragender Bestandteil des Gewaltentrennungsgrundsatzes und damit der Rechtsstaatlichkeit, ist im Grundgesetz jedenfalls der Formulierung nach dahin abgewandelt, daß die Rechtsprechung an ,Gesetz und Recht' gebunden ist (Art. 20 Abs. 3). Damit wird nach allgemeiner Meinung ein enger Gesetzespositivismus abgelehnt. Die Formel hält das Bewußtsein aufrecht, daß sich Gesetz und Recht zwar faktisch im allgemeinen, aber nicht notwendig und immer decken. Das Recht ist nicht mit der Gesamtheit der geschriebenen Gesetze identisch. Gegenüber den positiven Satzungen der Staatsgewalt kann unter Umständen ein Mehr an Recht bestehen [...]. Der Richter ist nach dem Grundgesetz nicht darauf verwiesen, gesetzgeberische Weisungen in den Grenzen des möglichen Wortsinns auf den Einzelfall anzuwenden. Eine solche Auffassung würde die grundsätzliche Lückenlosigkeit der positiven staatlichen Rechtsordnung voraussetzen, ein Zustand, der als prinzipielles Postulat der Rechtssicherheit vertretbar, aber praktisch unerreichbar ist. [...] Die richterliche Entscheidung schließt dann diese Lücke nach den Maßstäben der praktischen Vernunft und den ,fundierten allgemeinen Gerechtigkeitsvorstellungen der Gemeinschaft'. Diese Aufgabe und Befugnis zu ,schöpferischer Rechtsfindung' ist dem Richter — jedenfalls unter der Geltung des Grundgesetzes — im Grundsatz nie bestritten worden. Die obersten Gerichtshöfe haben sie von Anfang an in Anspruch genommen. Das Bundesverfassungsgericht hat sie stets anerkannt.« Das positive Recht ist also zentraler Teil der Rechtserzeugungsprozeduren, das Recht wird aber nur für jeden Einzelfall gleichsam einmalig durch die Anwendung dieser Prozeduren erzeugt.

Interessant ist in diesem Zusammenhang auch die rechtsökonomische Diskussion um Regeln und Verhaltensstandards (dazu schon oben Fn. 22), derzufolge sich der Unterschied von Gesetz und Recht — aus einem anderen Blickwinkel - auch eher graduell denn (wie hier) dichotom darstellen lässt; vgl. etwa Kaplow, Rules versus Standards, 42 Duke L.J. 557 (1992); Diver, The Optimal Precision of Administrative Rules, 93 Yale L.J. 65 (1983).

Vgl. auch Engel, Learning the Law, Preprints of the Max Planck Institute for Research on Collective Goods 2004/5, 2004, 1 (erscheint in: JOIE 2008); Lüdemann, Edukatorisches Staatshandeln. Steuerungstheorie und Verfassungsrecht am Beispiel der staatlichen Förderung von Abfallmoral, Baden-Baden 2004, 38 f.; siehe aber Benda, Die Wahrung verfassungsrechtlicher Grundsätze im Steuerrecht, DStZ 1984, 159 (163), der ohne Umschweife davon ausgeht, dass der Bürger seine »Rechte und Pflichten« kennen kann (und wohl auch kennt).

87 Die bloße Existenz der Gesetzesblätter legt freilich das Gegenteil nahe: Durch sie sollen die Rechtsunterworfenen ja gerade in die Lage versetzt werden, Kenntnis vom positiven Recht zu erlangen, die Gesetze sollen jedermann zugänglich sein, nicht lediglich einer besonderen Kaste; vgl. dazu statt vieler etwa Maurer, in: Bonner Kommentar zum Grundgesetz, Art. 82, Rz. 88ff.. Auch ein Blick in die Rechtsgeschichte - mit Verkündplätzen und Ausrufern - legt nahe, dass die Gesetze (aber nicht allein sie) einem möglichst großen Publikum tatsächlich bekannt gemacht werden sollten (vgl. dazu etwa H. Lück, Verkündplätze, in: Handwörterbuch zur deutschen Rechtsgeschichte, Band V, S. 747 f. [m. w. N.]). Aber das alles ändert freilich nichts an der hier geschilderten Realität.

$88 \mathrm{Zu}$ den Anforderungen an die Zugänglichkeit einer Norm aus Art. 10 Abs. 2 EMRK vgl. Engel, Privater Rundfunk vor der Europäischen Menschenrechtskonvention, Habil., Baden-Baden 1993, 63 f., 451 (m. zahlr. Nachw.). 
bestenfalls vage Rechtskenntnis; ${ }^{89}$ angesichts von Dichte und Interdependenzen gesetzlicher Normen kann auch mehr von ihnen nicht erwartet werden. Folglich richtet der Normadressat sein Verhalten allfällig an seinem Rechtsempfinden ${ }^{90}$, nicht aber am Gesetzwortlaut (am »positiven Recht«) aus. Nur in Ausnahmefällen — etwa, wenn es eine Führerscheinprüfung ${ }^{91}$ abzulegen gilt oder wenn »der Verbraucher« einmal die zu seiner Aufklärung bestimmten Pflichthinweise studiert - hat er (temporär) Kenntnis von einzelnen positiven Rechtsnormen. ${ }^{92}$ Indessen versteht entgegen der Forderungen des Bundesfinanzhofs ${ }^{93}$ selbst der Bundespräsident (und Ökonom) Köhler, wie einst schon sein Vorgänger Herzog, die eigene Steuererklärung nicht. ${ }^{94}$ Und welcher Stalker wusste wohl, dass er mit dem »beharrlichen Nachstellen« am 30. März 2007 besser aufhören sollte, weil es seit dem 31. März unter Strafe steht? Freilich, er hätte vom neuen Gesetz wissen können. An diese theoretische Möglichkeit knüpft das Recht im Allgemeinen an, wenn es den Adressaten für die Nichtbefolgung einer sich an ihn richtenden Norm haften lassen will: Die Gesetzeskenntnis der Bürger ist insofern eine für das Funktionieren des Rechts elementare Fiktion, die Unkenntnis des Gesetzes wird ihm zugerechnet. Beides ist gleichsam selbst Norm. Daraus kann aber nicht geschlossen werden, dass der Normadressat jedes Gesetz auch verstehen können muss. ${ }^{95}$ Denn selbst wenn der Bürger das Gesetz kennen würde, heißt das noch nicht, dass er das Recht verstehen kann. Das gilt umso mehr, als zum Rechtsverständnis die Kenntnis des Gesetzestextes allein nicht genügt; sie ist in aller Regel notwendige, nicht aber hinreichende Bedingung. Ohne Beachtung etwa der Rechtsprechung oder von Durchführungsverordnungen und ohne profunde systematische Kenntnisse lässt sich aus dem Gesetz kein Recht gewinnen. ${ }^{96}$ Schon 1678 stellte Leibniz fest, dass es nicht möglich sei, das Recht zu kennen, ohne über eine sehr große Bibliothek zu verfügen. ${ }^{97}$ Ohne kundigen Rat kommt der Laie beim Bemühen, die allenthalben komplexen rechtlichen Regelungen zu erfassen, daher heute kaum aus. ${ }^{98}$ Besonders drastisch ist dies an europarechtlich fundierten Normen nachzuvollziehen: Manches Gesetz erscheint als einfaches Bundesrecht, beruht aber auf einer Richtlinie, ${ }^{99}$ für die

89 Vgl. Maurer, in: Bonner Kommentar zum Grundsgesetz, Art. 82, Rz. 93. Dazu auch die böse Glosse von Vormbaum, Neues aus der Bauhütte des Rechts, oder: Geist und Buchstabe, JZ 2008, 244.

90 Vgl. zur Entwicklung des Rechtsempfindens Hammer/Keller, Überlegungen zur Entstehung des Rechtsempfindens aus entwicklungspsychologischer Sicht, in: Lampe, Zur Entwicklung von Rechtsbewußtsein, Frankfurt am Main 1997, $152 \mathrm{ff}$. .

91 Engel, Learning the Law, MPI-Preprints 2004/5 (erscheint in: JOIE 2008), 1. Als weiteres Beispiel könnten die Schilder im Straßenverkehr dienen, wenn man ihnen denn Normqualität beimisst.

92 Vgl. zur tatsächlichen Rechtskenntnis aus jüngster Zeit die Studie von MacCoun u.a., Do Citizens Know Whether Their State Has Decriminalized Marijuana? A Test of the Perceptual Assumption in Deterrence Theory, Preprint, 2008, http://ssrn.com/paper=1120930 (abgerufen am 13. Mai 2008). — Anderes gilt für konkret-individuelle Regelungen, die sich unmittelbar an den Adressaten richten.

93 BFH, Beschl. v. 6. September 2006, XI R 26/04, juris, Abs. 43.

94 So Bundespräsident Horst Köhler in der ARD-Sendung Sabine Christiansen am 24. Juni 2007, vgl. Presseund Informationsamt der Bundesregierung, Medienmonitoring, Medienspiegel Inland, 25. Juni 2007, S. 10 f..

95 Diese Zusammenhänge verkennt etwa Kreppel, Persönlichkeitsrecht und Abgabepflicht, in: Schwarze/Graf Vitzthum (Hg.), Grundrechtsschutz im nationalen und internationalen Recht, 119 ff..

96 Vgl. Hassemer, Gesetzesbindung und Methodenlehre, ZRP 2007, 213 (214, I a.E. und II.3). Vgl. auch anschaulich Vormbaum, Neues aus der Bauhütte des Rechts, JZ 2008, 244.

97 Zitiert nach Ost/van de Kerchove, Constructing the Complexity of the Law, in: Wintgens (Hg.), The Law in Philosophical Perspectives, 147 (147).

98 Vgl. Borell/Schemmel, Steuervereinfachung, DStZ 1987, 110 (112).

99 Schätzungen zufolge gehen $70 \%$ der neuen Gesetze und Verordnungen auf Bundesebene auf EU-Recht zurück, so Karpen, Empfehlungen zur Qualitätsverbesserung von Gesetzen, ZRP 2008, 97 (98). 
die strengen Anforderungen des Europäischen Gerichtshofes an richtlinienkonforme Auslegung gelten. Soll diese Norm richtig ausgelegt werden, dann muss der Leser nicht nur die Richtlinie kennen, sondern etwa auch wissen, ob diese einen Mindest-, einen Höchst- oder einen fixen Standard etablieren soll; es bedarf also intimer Kenntnis der (ggf. ungeschriebenen) Interdependenzen einer rechtlichen Regelung. Ein Weiteres kommt hinzu: Die Rechtssprache ist eine Fachsprache, und sie muss es, um der Rechtssicherheit willen, auch sein. ${ }^{100}$ Das impliziert nicht, dass das Verständnis von Rechtstexten eine sprachliche Herausforderung ist, sondern dass es in aller Regel am fehlenden — rechtlichen - Vorverständnis scheitert; ${ }^{101}$ umgekehrt verhilft die Fachsprache dem Rechtskundigen dazu, die relative Komplexität reduzieren zu können. ${ }^{102}$ Die Technizität des Rechts kann schließlich den Bürger ebenso treffen, wenn er sich gegen eine mit einem Planfeststellungsverfahren in Verbindung stehende Enteignung zur Wehr setzen will, wie wenn er in die Verlegenheit kommt, eine fehlgegangene Banküberweisung nach den Regeln der ungerechtfertigten Bereicherung rückgängig machen zu müssen. All diese Erkenntnisse werden durch die Juristenausbildung sehr eindrücklich verdeutlicht, stehen doch nicht bloße Gesetzeskenntnis oder Fragen der Sachverhaltsermittlung (also etwa Zeugenvernehmung, Graphologie, Forensik) im Mittelpunkt, sondern die Vermittlung dogmatischer Fertigkeiten. ${ }^{103}$

Vor dem Hintergrund dieser nüchternen Sicht auf die allgemeine Normenkenntnis verliert auch ein in der Literatur zur Normenklarheit oft unausgesprochen mitgedachtes Ideal sein Fundament, dass nämlich das Recht zu allen seinen Adressaten »sprechen« möge. ${ }^{104}$ Demnach sollte das Recht für alle, von denen es Befolgung verlangt, verständlich sein. Aus diesem Ideal wird gefolgert, dass das jeweils erforderliche Maß für Klarheit davon abhängt, welche konkrete Personengruppe vom Gesetz angesprochen ist - also ob es etwa den Verbraucher betrifft oder den Kraftwerksbetreiber. ${ }^{105}$ Nur weil das personengenau wegen der Heterogenität der Adressaten praktisch unmöglich ist, wird als Kompromiss für jeden Regelungsbereich auf einen idealisierten, fiktiven Normadressaten abgestellt. ${ }^{106}$ Auch diese Überlegungen zum Bezugspunkt des Gebots

100 Duve/Weirich, Die Verständigung zwischen dem Bürger und den Juristen kann verbessert werden, in: Radtke, Die Sprache des Rechts und der Verwaltung, Stuttgart 1981, 119 (120 f.); Papier, Verfassungsrechtliche Grundlagen der Besteuerung, in: Brandt (Hg.), Für eine bessere Steuerrechtskultur, 25 (29); vgl. Schröder/Würdemann, Verständlichere Gesetzessprache — Institutionalisierung der Sprachprüfung im Gesetzgebungsverfahren, ZRP 2007, 231, die im Streben nach einer verständlicheren Gesetzessprache eine »dauerhafte Optimierungsaufgabe« sehen. - Auch dass gem. § 42 Abs. 5 der Gemeinsamen Geschäftsordnung der Bundesministerien (GGO) Gesetzentwürfe grundsätzlich dem Redaktionsstab der Gesellschaft für deutsche Sprache im Bundestag zuzuleiten sind, darf darüber nicht hinwegtäuschen.

101 Ein schönes Beispiel aus dem Bereich des Strafrechts, für das gemeinhin gefordert und angenommen wird, es sei allen Rechtsgenossen verständlich: Vormbaum, Neues aus der Bauhütte des Rechts, JZ 2008, 244.

102 Das verkennt Herzog, Gesetzgebung und Einzelfallgerechtigkeit, NJW 1999, 25, wenn er fordert, dass die Gesetze so formuliert sein müssen, dass sie den Laien ansprechen. — Der hier dargestellten Zusammenhang findet sich aus der Warte der Systemtheorie und systemischer Komplexität in überaus treffende Worte gekleidet bei Di Fabio, Offener Diskurs und geschlossene Systeme. Das Verhältnis von Individuum und Gesellschaft in argumentations- und systemtheoretischer Perspektive, Diss., Berlin 1991, 147.

103 Vgl. auch Hassemer, Gesetzesbindung und Methodenlehre, ZRP 2007, 213 (214).

104 Etwa Herzog, Gesetzgebung und Einzelfallgerechtigkeit, NJW 1999, 25.

105 Aus der Rechtsprechung etwa: BVerfG, Beschl. v. 26. September 1978, 1 BvR 525/77, BVerfGE 49, 168 (181); Beschl. v. 24. November 1981, 2 BvL 4/80, BVerfGE 59, 104 (114). Statt vieler Stimmen aus der Literatur hier nur Duve/Weirich, Die Verständigung zwischen dem Bürger und den Juristen, in: Radtke, Die Sprache des Rechts und der Verwaltung, 119 und Kreppel, Persönlichkeitsrecht und Abgabepflicht, in: Schwarze/Graf Vitzthum (Hg.), Grundrechtsschutz im nationalen und internationalen Recht, 119 (129).

$\mathrm{Zu}$ den rechtsstaatlichen Problemen dieser Idealisierung des Adressaten unten IV.3e)bb) (S. 28). 
der Normenklarheit vermögen indessen schon deshalb nicht zu überzeugen, weil auch sie davon ausgehen, dass der Adressat das Gesetz zur Kenntnis nehme und - entscheidender - ihm diese Gesetzeskenntnis nützlich ist, weil er aus dem Gesetz folgern könne, was Recht ist. Dass diese Annahmen nicht haltbar sind, hat sich indessen erwiesen.

Insofern ist die Forderung des Bundesfinanzhofes, der Betroffene müsse »anhand der gesetzlichen Regelung die Rechtslage so erkennen können, dass er sein Verhalten daran auszurichten vermag « ${ }^{107}$ eine völlig an der Realität vorbei gehende Anforderung, die nur mit rechtspolitischen Motiven zu erklären ist. Es sind kaum Regelungsbereiche ersichtlich, in denen das heute noch möglich wäre. ${ }^{108}$ Nicht einmal für den Bereich des Strafrechts ist diese Annahme plausibel. ${ }^{109}$ Die komplizierten Sachverhalte unserer Welt lassen sich kaum mehr in kurzen Hauptsätzen regeln. ${ }^{110}$ Auch bringt die Gesetzeskenntnis dem Normadressaten regelmäßig für die Kenntnis des Rechts nichts; selbst in Fällen, in denen das Recht nicht über das Gesetz hinausgeht, kann er sich dieses Umstandes nämlich nicht gewiss sein. Daher kann es schon aus diesem Grunde letztlich nicht sinnvoll sein, sich für die Bewertung der Komplexität einer Norm an der objektivierten Sicht der Adressaten zu orientieren.

\section{b) Theorie: Wirkungsweise des Rechts}

Wir wissen sehr wenig über die tatsächliche Wirkungsweise des Rechts. Es gibt plausible Annahmen darüber, wie das Recht auf Entscheidungen wirkt, wenn es dem Entscheidenden bekannt ist; derlei Annahmen lassen sich beispielsweise aus der ökonomischen Rationaltheorie ableiten. Wenn man nun aber wie hier davon ausgeht, dass die Normadressaten das positive Recht für gewöhnlich nicht oder nur unvollständig kennen, dann ist auch fraglich, ob die Wirkungsmechanismen des Rechts verlangen, dass jeder Adressat die Gesetze versteht, bzw. ob die Rechtstreue vom Gesetzesverständnis abhängt. ${ }^{111}$ Die Frage richtet sich damit gegen die dem Gebot der Normenklarheit fundamental zugrundeliegende Annahme, dass dem Recht nur folgen kann, wer das Gesetz versteht. Die Wirkungsweise des Rechts ist bislang allenfalls Gegenstand rechtssoziologischer oder rechtsphilosophischer ${ }^{12}$ Betrachtung gewesen, im theoretischen, dogma-

107 BFH, Beschl. v. 6. September 2006, XI R 26/04, juris, Abs. 43 (Hervorhebung durch Vf.); vgl. Nachweise bei Fn. 72.

108 Bei einer Untersuchung der in den ersten zwei Jahren der 16. Legislaturperiode erlassenen 698 formellen Gesetzen und Rechtsverordnungen wurden 277 Gesetze »negativ bewertet, was bedeutet, dass die Vorschriften für den Anwender entweder unverständlich oder zu technisch sind. Nur insgesamt sechs Gesetze konnten als sprachlich gelungen bezeichnet werden. [...] Über 110 Gesetze und Verordnungen gehen so weit ins Detail, dass der Gesetzgeber sich nur durch umfangreiche Anlagen zu helfen weiß.« (Karpen, Empfehlungen zur Qualitätsverbesserung von Gesetzen, ZRP 2008, 97 (99)).

109 Dafür lassen sich zahllose Beispiele finden; aus neuerer Zeit und recht anschaulich etwa Vormbaum, Neues aus der Bauhütte des Rechts, JZ 2008, 244.

110 Herzog, Gesetzgebung und Einzelfallgerechtigkeit, NJW 1999, 25.

111 Dies ist indessen der argumentative Eckstein vieler Ansätze, die per se eine Reduzierung der Regelungskomplexität von Normen verlangen, etwa bei Kreppel, Persönlichkeitsrecht und Abgabepflicht, in: Schwarze/Graf Vitzthum (Hg.), Grundrechtsschutz im nationalen und internationalen Recht, 119 (126). Auch das Bundesverfassungsgericht geht von einer »gesetzliche[n] Verhaltenssteuerung durch Vorhersehbarkeit« aus, vgl. BVerfG, Urt. v. 20. März 2002, 2 BvR 794/95, BVerfGE 105, 135 (173).

112 Erhellend etwa Ost/van de Kerchove, Constructing the Complexity of the Law, in: Wintgens (Hg.), The Law in Philosophical Perspectives, 147 (159 ff., m. zahlr. w. N.). 
tischen oder empirischen Diskurs taucht sie dagegen nicht als eigenständige Fragestellung auf. ${ }^{113}$ Das verwundert angesichts der Allgegenwärtigkeit des Postulats der Wirklichkeitsbezogenheit des Rechts. Hier ist weder der Raum, eine eigenständige Theorie zu entwickeln, noch auch nur bestehende Konzeptionen zu rezipieren. Für die Zwecke dieser Untersuchung ist es ausreichend festzustellen, dass das Recht - ganz zu schweigen vom eigentlichen Gesetzestext — nur in den seltensten Fällen unmittelbare Auswirkungen auf das Verhalten der Bürger hat. ${ }^{114}$ Dass unsere stark durch das Recht vorgeprägte oder gar konstruierte Welt den Anschein hat, nach den Regeln des Rechts zu funktionieren, kann nicht damit begründet werden, dass die Adressaten die Gesetze kennen.

Möchte man verstehen, wie das Recht wirkt, dann ist zunächst die »alltägliche« Rechtsbefolgung von jener in solchen Situationen zu unterscheiden, bei denen für den Normadressaten ausnahmsweise viel auf dem Spiel steht. ${ }^{115}$ Während im letztgenannten Fall, wie oben beschrieben, das geltende Recht (d.h. nicht nur das gültige Gesetz) ggf. aufwendig und unter Hinzuziehung von Intermediären ermittelt wird, ist derlei für die alltägliche Rechtsbefolgung nicht zu beobachten. Um einer Erklärung für die weitgehende Übereinstimmung von beobachtetem Verhalten und Recht auch in diesen Situationen näher zu kommen, ist auf zwei Dinge zu schauen: Zum einen ist der Frage nachzugehen, wie aus historischer Perspektive Gesetz und Recht entstehen. Zum anderen ist aus sozial- und entwicklungspsychologischer Warte $\mathrm{zu}$ fragen, wie Normen - und spezieller: Rechtsnormen — vom Individuum und von Gruppen internalisiert werden. ${ }^{116}$ Hinsichtlich der ersten Frage sind die Fälle, in denen der Gesetzgeber (in der Regel mit einiger Verzögerung) vorherrschenden oder zumindest prominent geäußerten gesellschaftlichen Anschauungen folgt (z.B. bei der Anerkennung und Eintragung gleichgeschlechtlicher Lebenspartnerschaften nach dem LPartG oder bei der erwähnten Einführung der Strafbarkeit des Stalking), von jenen zu scheiden, in denen der Gesetzgeber durch das Recht auf die Gesellschaft einzuwirken versucht (z.B. bei Rauchverboten oder Mülltrennung ${ }^{117}$ ). ${ }^{118}$ Wird die Gesetzeslage in den erstgenannten Fällen sozialen Normen angeglichen, so kann nicht verwundern, dass es den Anschein hat, als folgten die Normadressaten dem Gesetz. Aber auch in den letztgenannten Fällen

113 Verschiedene - auch vor- oder nachgelagerte Fragestellungen — finden sich etwa bei Bung/Valerius (Hg.), Normativität und Rechtskritik: Tagungen des Jungen Forums Rechtsphilosophie (JFR) in der Internationalen Vereinigung für Rechts- und Sozialphilosophie (IVR) im September 2006 in Würzburg und im März 2007 in Frankfurt am Main, Stuttgart 2007; Diekmann, Die Befolgung von Gesetzen: Empirische Untersuchungen zu einer rechtssoziologischen Theorie, Berlin 1980; Engel, Learning the Law, MPI-Preprints 2004/5 (erscheint in: JOIE 2008); Friedman, The legal system: a social science perspective, New York 1977; Jones, The efficacy of law, Evanston, Ill. 1968; Lampe, Zur Entwicklung von Rechtsbewußtsein; Pavlakos, Our knowledge of the law: objectivity and practice in legal theory, Oxford 2007.

114 Engel, Learning the Law, MPI-Preprints 2004/5 (erscheint in: JOIE 2008), 5 f. (m.w.N.). Die folgende Darstellung fußt in weiten Teilen auf Engels Ausführungen in der hier zitierten Studie. Vgl. auch Hertwig, Do legal rules rule behaviour?, in: Gigerenzer/Engel (Hg.), Heuristics and the Law, Cambridge, Mass. 2006,391 ff..

115 In der Entscheidungsforschung werden die Zustände als »low« bzw. »high stake« bezeichnet.

116 Interessante Einsichten zur Entwicklung von Rechtsempfinden vermitteln Hammer/Keller, Rechtsempfinden, in: Lampe, Zur Entwicklung von Rechtsbewußtsein, 152 ff..

117 Vgl. Lüdemann, Edukatorisches Staatshandeln.

118 Hier spiegelt sich die alte Streitfrage nach Aufgabe und Funktion des Rechts: Soll es das immanente Naturrecht abbilden bzw. kodifizieren oder dient es in erster Linie der Ausübung von Herrschaft? 
wird die Rechtsbefolgung nur zu einem geringen Teil vom Gesetz geleitet. ${ }^{119}$ Die Gesetzeskenntnis scheint jedenfalls weitgehend irrelevant. Im Hinblick auf die Internalisierung des Rechts ist vielmehr die Annahme plausibel, dass das Recht mittelbar erlernt wird, ${ }^{120}$ und dass es einen noch nicht genauer untersuchten Einfluss auf die Bildung und Stärkung sozialer Normen und Sitten hat, die dann verhaltensbestimmend wirken. ${ }^{121}$ Das Recht macht sich dabei die weitverbreitete Bereitschaft des Einzelnen zunutze, herrschenden Sitten zu folgen. ${ }^{122}$ Nur in seltenen Zweifelsfällen wird zur Orientierung das Gesetz im Sinne eines Regelbuches zu Rate gezogen. ${ }^{123}$ Neben den erwähnten Gründen spielt dafür, dass dies so selten geschieht, auch der Umstand eine Rolle, dass die Gesetze oft nicht leicht verfügbar sind und dass den Normadressaten klar ist, dass vom Gesetz nicht ohne Weiteres auf das Recht geschlossen werden kann. Völlig offen ist, wie sich in dieser Gemengelage die Klarheit von Gesetzen auswirkt. Weder theoretisch noch empirisch untersucht ist etwa die Frage, ob einfach verständliche Gesetze (z.B. Verkehrsschilder oder sonstige Piktogramme ${ }^{124}$ ) überhaupt häufiger befolgt werden, als auf andere Weise internalisierte, komplexere Normen. Plausibel erscheint die Annahme, dass Gesetze (soziale) Normen dann zu stärken oder gar zu etablieren vermögen, wenn ihr Regelungsgehalt bzw. ihre Verhaltensanforderung verhältnismäßig leicht einsichtig und erlernbar ist, die also mit einer möglichst geringen Dichte und möglichst geringen Interdependenzen auskommen. Umgekehrt sind aber auch unschwer Fälle denkbar, in denen höhere Komplexität sachgerechtere Ergebnisse ermöglicht. ${ }^{125}$

An der Schnittstelle von Wirkungsweise und Funktion des Rechts darf außerdem die bedeutende Rolle der Gesetzesauslegung und Rechtsanwendung durch Juristen - etwa in Verwaltung und Rechtsprechung oder durch andere Intermediäre - nicht übersehen werden. ${ }^{126}$ Zum einen ist eine wichtige Funktion des Rechts nicht auf die Adressaten, sondern auf den Staat selbst be-

119 Dazu eingehend Lüdemann, Edukatorisches Staatshandeln, $61 \mathrm{ff}$.

120 Dazu Engel, Learning the Law, MPI-Preprints 2004/5 (erscheint in: JOIE 2008), dessen Theorie zufolge die Bildung von Rechtskenntnis und Rechtsverständnis in erster Linie in Kindheit und Adoleszenz erfolgt, und zwar in aller Regel durch Deduktion, sei es durch Nachahmung oder aufgrund von Sanktionen dafür, dass kontextabhängige Verhaltenserwartungen der Umwelt nicht erfüllt werden. Institutionen wie Familie und Schule spielen dabei eine wichtige Rolle, indem sie prozedurales und materielles Wissen vermitteln. Anpassungen dieses Wissens an Veränderungen im Recht werden nach der grundprägenden Phase inkrementell vorgenommen. Hertwig, Do legal rules rule behaviour?, in: Gigerenzer/Engel (Hg.), Heuristics and the Law, 391 (397 ff.) zufolge findet soziales Lernen anhand einer Imitations-Heuristik statt.

121 Letztgenannter Ansatz wird zurzeit unter dem Schlagwort »expressive law«, hinter dem sich eine Vielzahl verschiedener theoretischer Ansätze verbirgt, in der englischsprachigen Literatur ausführlich diskutiert. Aus entscheidungstheoretischer Sicht geht es in erster Linie um das Problem der Schaffung und Auswahl von Gleichgewichten, auf die sich die Akteure koordinieren können. Zum Ganzen etwa Magen, Fairness, Eigennutz und die Rolle des Rechts. Eine Analyse auf Grundlage der Verhaltensökonomik, in: Engel/Englerth (Hg.), Recht und Verhalten. Beiträge zu Behavorial Law and Economics, Tübingen 2007, $261 \mathrm{ff..}$

122 Vgl. Engel, Learning the Law, MPI-Preprints 2004/5 (erscheint in: JOIE 2008), 6. In diesem Zusammenhang stellen sich interessante Fragen zu Interaktion, Kausalität und Wirkungsrichtung vom oft beschworenen und zunehmend verloren gesehenen »gesellschaftlichen Konsens« einerseits, und der Bereitschaft, sich einem gesellschaftlichen Konsens und vorherrschenden Sitten anzuschließen oder zu beugen andererseits.

123 Engel, Learning the Law, MPI-Preprints 2004/5 (erscheint in: JOIE 2008), 5 f. (m.w.N.).

124 Sofern überhaupt Normen i.e.S. vorstellbar sind, die eine solch ausgeprägt niedrige Komplexität aufweisen.

125 Vgl. etwa BVerfG, Urt. v. 20. März 2002, 2 BvR 794/95, BVerfGE 105, 135 (173), sowie das Beispiel zum geistigen Eigentum unten unter IV.3.c) bei Fn. 135.

126 Dies gilt in geringerem Maße auch etwa für Rechtsanwälte und andere Intermediäre oder die dogmatische Rechtswissenschaft. 
zogen: Ungleichbehandlungen und Willkür sollen ausgeschlossen werden. ${ }^{127}$ Insofern harmonisiert das Recht also die Entscheidungen und Handlungen des Akteurs Staat. Gleichzeitig setzen sich die Wirkungen des Rechts damit auch bei den eigentlichen Normadressaten fort. Denn wo Verwaltung und Gerichte das Recht einheitlich durchsetzen, müssen die Normadressaten folgen; und sie werden sich jedenfalls auf mittlere Sicht auch anpassen. Auch über die einheitliche Anwendung des Rechts durch Verwaltung und Gerichte hinaus dürfte Intermediären eine wichtige Rolle bei der Vermittlung von Rechtsverständnis und bei der Internalisierung von Rechnormen zukommen. Ein Gebot, die positiven Normen per se einfach zu gestalten, lässt sich nach alledem - mangels Kenntnis der zugrunde liegenden Mechanismen - auch dann nicht schlüssig begründen, wenn man die Wirkungsweise des Rechts in den Blick nimmt.

\section{c) Ökonomie: Kosten der Komplexität und »optimale Komplexität»}

Ein häufig gegen komplexe Normen - und damit für eine strenge Prüfung der Normenklarheit etwa anhand des Verständnisses des Normadressaten - ins Feld geführtes Argument ist ökonomischer Provenienz: Höhere Komplexität erschwere das Verständnis ${ }^{128}$ und verursache damit höhere (direkte und indirekte) Kosten; ${ }^{129}$ damit sinke die Effizienz, Wohlfahrtsverluste seien die Folge. Die Komplexität des Rechts sei daher möglichst gering zu halten.

Es ist zutreffend, dass die sparsame Kenntnis des juristischen Laien vom positiven Recht auch vor dem Hintergrund nachvollziehbar ist, dass der jeweilige Betroffene für die Vorbereitung einer Entscheidung nur über knappe Ressourcen verfügt: Er kann etwa in zeitlicher, kognitiver und monetärer Hinsicht nicht für jede Entscheidung beliebig viel Aufwand treiben, um sich vollständig zu informieren. Das bedeutet, dass es rational ist, sich ex ante nur dort zu informieren, wo der von der Information erwartete Nutzen (der den Erwartungswert des Schadens bei unvollständiger Information einschließt) größer ist, als die aufgewendeten Such- und Informationskosten (compliance costs). ${ }^{130}$ In allen übrigen Fällen wird die Information mit einer gewissen Wahrscheinlichkeit (z.B. im Streitfall) ex post beschafft. ${ }^{131}$ Ist das Recht (oder bisweilen der Sachverhalt) zu komplex, wird in diesen Situationen - kostensparend — oft verhandelt und ver-

127 Dazu, dass dies eine spezifische Aufgabe von Bestimmtheit/Klarheit ist Papier/Möller, Das Bestimmtheitsgebot und seine Durchsetzung, AöR 122 (1997), 177 (189 ff.).

128 Dazu oben II.2.

129 Vgl. Epstein, Simple rules for a complex world, Cambridge, Mass. 1995, 23 ff.; vgl. Borell/Schemmel, Steuervereinfachung, DStZ 1987, 110 (114). Das BVerfG sieht — dieser Argumentation ähnlich — das Gebot der Normenklarheit verletzt, wenn es durch eine von Interdependenzen verursachte Komplexität nur noch dem Experten möglich ist, sämtliche Eingriffsvoraussetzungen mit vertretbarem Aufwand zu erkennen (Beschl. v. 3. März 2004, 1 BvF 3/92, BVerfGE 110, 33 (53 f.)).

130 Vgl. etwa Kaplow, A Model of the Optimal Complexity of Legal Rules, 11 JLEO 150 (1995).

131 Dieser Befund entspricht allgemeiner Beobachtung, lässt sich aber nur schwer anhand von Felddaten empirisch belegen. Indizien sind etwa, dass nach Informationen des Statistischen Bundesamtes (Korrespondenz und Telefonate im Juli 2007) die realen marginalen Steuersätze in den höheren Einkommensklassen im Vergleich zur gesetzlichen Steuerprogression flacher und negativ mit den auf Steuer- und Rechtsberatung aufgewendeten Werbungskosten korreliert sind; das lässt darauf schließen, dass derlei Ausgaben vor allem dort getätigt werden, wo von »Steuergestaltung« in besonderem Maße profitiert wird. Vgl. Auch Lang u.a., On income tax avoidance: the case of Germany, JPE 66 (1997), 327. 
glichen. ${ }^{132}$ Dass zum Norm- und Rechtsverständnis Rechtskundigkeit erforderlich ist, über die der Adressat in der Regel nicht verfügt, verteuert die allgemeinen Kosten der Informationsbeschaffung und kann es notwendig machen, einen Intermediär einzuschalten. Auch der Grad der Komplexität einer Norm hat Einfluss auf die Kosten: Was die Mitgliederzeitschrift des ADAC erklären kann, bedarf keiner Erläuterung durch Spezialisten. Bemerkenswert ist in diesem Zusammenhang, dass die mangelnde Gesetzeskenntnis der Normadressaten und ihre unzureichende Fähigkeit zur Komplexitätsbewältigung weniger ein individuelles kognitives Problem, denn ein generelles strukturelles Problem darstellt. ${ }^{133}$ Doch es gibt kein vollständiges Bild, schaut man nur auf die individuell zusätzlich anfallenden Kosten. Zuvörderst kann die zu höherer Komplexität führende rechtliche Regelung selbst zu größerer gesamtwirtschaftlicher Wohlfahrt führen, die die individuellen Rechtsbefolgungskosten aufwiegt. ${ }^{134}$ Ein klassisches Beispiel aus der ökonomischen Analyse des Rechts mag das veranschaulichen: ${ }^{135}$ Wenn es keinen Schutz für geistiges Eigentum gibt, hat kein Akteur am Markt einen Anreiz, Forschung und Entwicklung zu betreiben, denn die Kosten dafür fielen bei ihm an, während auch seine Wettbewerber - als Trittbrettfahrer — am Nutzen seiner Investitionen partizipierten. Um dieses Dilemma aufzulösen und Anreize für die technische Entwicklung zu setzen, bedarf es rechtlicher Institutionen (etwa Schutzrechten). Diese erhöhen freilich die Komplexität ${ }^{136}$ von Gesetz und Recht (insbesondere die Dichte) und die individuellen Kosten der Rechtsbefolgung (z.B. Ermittlung des Rechts; Prüfung einschlägiger Schutzrechte Dritter bei der Entwicklung neuer Produkte; Anmeldung von Patenten). Ähnliches gilt, wenn es um die Herstellung oder den Schutz öffentlicher Güter geht, was sich beispielsweise im Hinblick auf den Umweltschutz am Emissionshandel zeigen lässt.

Letztlich muss in jedem Fall geprüft werden, ob die sozialen Wohlfahrtsgewinne die Summe der privaten Kosten überwiegen. ${ }^{137}$ Weil die Quantifizierung Schwierigkeiten bereitet, können ökonomische Modelle bei der Identifizierung von Faktoren und Situationen helfen, in denen (höhere) Komplexität ökonomisch sinnvoll — effizient — ist; die Frage lässt sich dann auch als Optimierungsproblem formulieren, mit dem Ziel, Aussagen über die theoretische optimale Kom-

132 Das ist beispielsweise im Arbeitsrecht zu beobachten, wenn unklar ist, ob bei einer Kündigung die Sozialauswahl richtig erfolgt ist.

133 In der verhaltenswissenschaftlichen Literatur (Stichwort »bounded rationality«) — etwa in den Schriften von Epstein und Gigerenzer — wird der Schwerpunkt der Betrachtung auf eine umstrittene Beschränkung der kognitiven Kapazitäten gelegt. Vgl. Gigerenzer/Engel (Hg.), Heuristics and the Law.

134 Größere Wohlfahrt lässt sich ggf. auch durch insgesamt »sachgerechtere« Ergebnisse fördern, vgl. dazu dann etwa BVerfG, Urt. v. 20. März 2002, 2 BvR 794/95, BVerfGE 105, 135 (173).

135 Die hier exemplarisch dargelegte Argumentationskette ist die »klassische« Begründung. Heute gibt es nicht nur im Zusammenhang mit der Diskussion um Softwarepatente und Schutzrechte in der Unterhaltungsindustrie - auch andere Ansätze, die diese Zusammenhänge in Zweifel ziehen. Zu beidem siehe (m.w.N.) Engel, Intellectual property as a carrot for innovators. Using game theory to show the limits of the argument, Preprints of the Max Planck Institute for Research on Collective Goods 2007/4, 2007.

136 Vgl. dazu die Stellungnahme der Patentanwaltskammer zum Verfahren 1 BvR 780/87 in BVerfGE 97,12 (23).

137 Wären Effizienz oder maximale Wohlfahrt die einzigen Maximen des verstaatlichten Gemeinwesens, dann könnte gefordert werden, dass der Staat für jede Norm den Nachweis erbringe, diese führe zu Wohlfahrtsgewinnen für die Gemeinschaft, wie dies im amerikanischen Diskurs bisweilen der Fall ist; vgl. Kaplow, A Model of the Optimal Complexity of Legal Rules, 11 JLEO 150 (1995), 150 f.; Kaplow, Accuracy, Complexity, and the Income Tax, 14 JLEO 61, 62 (1998). 
plexität zu treffen. ${ }^{138}$ Dabei ist durchaus zu konzedieren, dass manche rechtliche Regelung augenscheinlich suboptimal komplex ist, insbesondere komplexer als sie sein müsste. Es kann mit anderen Worten vorkommen, dass Gesetz und Recht komplex sind, weil sie schlecht sind ${ }^{139}$ — was indessen nicht bedeutet, dass komplexes Recht immer schlecht ist. ${ }^{140}$ Unter der Prämisse, dass der jeweilige Komplexitätsgrad des Rechts effizient ist, ${ }^{141}$ wird in aller Regel auch der Einsatz von Intermediären vorteilhaft (allokativ effizient) sein. ${ }^{142}$ Diesen Zusammenhang verkennt, wer verlangt, das Recht müsse grundsätzlich aus Sicht des Normadressaten verständlich sein: Schließlich erwartet auch kein Laie, einen Beinbruch nach den Regeln ärztlicher Heilkunst selbst behandeln zu können. ${ }^{143}$ Es kann mithin nicht pauschal davon ausgegangen werden, dass das Recht idealiter so simpel wie möglich sein sollte, und dass deshalb eine Orientierung am Verständnis des Normadressaten ökonomisch sinnvoll ist. ${ }^{144}$

\section{d) Verhalten: Reaktionen auf Komplexität}

Die Befunde der Verhaltenswissenschaften im Hinblick auf Komplexität ergeben ein weniger homogenes Bild. Von Interesse ist hier insbesondere die empirische Forschung zur Steuerhinterziehung. Es gilt aufgrund zahlreicher Experimente als gesichert, dass Steuerhinterziehung in einem engen Zusammenhang zur empfundenen Steuergerechtigkeit steht: Wer das Steuerrecht als ungerecht empfindet, hat (jedenfalls im Aggregat) eine größere Neigung, Steuern zu hinterziehen. ${ }^{145}$ In diesem Zusammenhang wird auch der Frage nachgegangen, wie sich Komplexität auf die empfundene Steuergerechtigkeit und letztlich auf Steuermoral und Rechtsbefol-

138 Vgl. etwa Kaplow, A Model of the Optimal Complexity of Legal Rules, 11 JLEO 150 (1995); Kaplow, Optimal Taxation, Harvard Law and Economics Discussion Paper No. 607, 2008 (erscheint in: The New Palgrave Dictionary of Economics, 2nd Edition); Kaplow, Accuracy, Complexity, and the Income Tax, 14 JLEO 61 (1998); Quandt, Complexity in Regulation, JPE 22 (1983), 199. Dafür, dass auch die Verständlichkeit der Sprache eine Optimierungsaufgabe darstellt etwa Schröder/Würdemann, Verständlichere Gesetzessprache, ZRP 2007, 231.

139 Vgl. Sendler, Rechtsstaat im Defizit?, in: Sendler/Redeker (Hg.), Recht — Gerechtigkeit — Rechtsstaat, 103 $(115,116 \mathrm{f}$.$) .$

140 Auch wenn die Mangelhaftigkeit eines Gesetzes grundsätzlich keinen Einfluss auf die Anwendung des Grundsatzes der Normenklarheit und damit auf die Verfassungsmäßigkeit hat, soll hier im Rahmen der ökonomischen Betrachtung der Vollständigkeit halber auf eine potenzielle Ursache hingewiesen werden: Es liegt nahe darüber nachzudenken, ob schlechte Gesetzesqualität mit dem Gesetzgebungsprozess in Verbindung steht. Die Ministerien, die Referentenentwürfe fertigen, haben selbst in erster Linie politische Anreize, oft haben nur Kompromisslösungen Aussicht, im Parlament verabschiedet zu werden und bisweilen gilt es, die eigene Wahlklientel zu bedienen. Vor diesem Hintergrund fällt es der entwerfenden Einrichtung nicht schwer, die Kosten für die Erarbeitung eines »guten« Gesetzes zu reduzieren. Das kann negative Externalitäten haben: das überkomplexe Recht verursacht Mehrkosten, die nicht beim Verursacher, sondern anderswo hängen bleiben. Zu diesen und weiteren politischen Gründen für unnötige Komplexität lesenswert Schuck, Legal Complexity, 42 Duke L.J. 1 (1992), 25 ff.; vgl. auch Sendler, Rechtsstaat im Defizit?, in: Sendler/Redeker (Hg.), Recht — Gerechtigkeit — Rechtsstaat, 103 (115, 116 f.).

141 Vgl. Schuck, Legal Complexity, 42 Duke L.J. 1 (1992), 8.

142 Vgl. die Stellungnahme der Patentanwaltskammer zum Verfahren 1 BvR 780/87 in BVerfGE 97, 12 (23).

143 Der Beinbruch ist allerdings realiter — gleichsam natürlich — komplex, so dass sich die Frage optimaler Komplexität nicht stellt, während es sich beim Recht um konstruierte Wirklichkeit handelt.

144 Anders: Epstein, The Optimal Complexity of Legal Rules, in: Gigerenzer/Engel (Hg.), Heuristics and the Law, 141 ff.; Epstein, Simple rules for a complex world; differenziert: Schuck, Legal Complexity, 42 Duke L.J. 1 (1992), 8, 19.

145 Kirchler/Maciejovsky, Steuermoral und Steuerhinterziehung, in: Frey u.a. (Hg.), Wirtschaftspsychologie, Göttingen 2006, 203 (214 ff.). 
gung auswirkt. Einerseits wird berichtet, Experimente zeigten, dass Komplexität der Steuergesetze zu Steuerwiderstand führe, was daran liege, dass der Steuerzahler den Eindruck habe, höhere Steuern zu zahlen, als das Gesetz vorsehe. ${ }^{146}$ Andererseits wurde herausgefunden, dass die subjektiv empfundene Komplexität ${ }^{147}$ nicht mit der empfunden (Un-)Gerechtigkeit im Zusammenhang steht. ${ }^{148}$ Das könne damit begründet werden, dass die Komplexität möglicherweise als Indikator für eine akkurate Erhebung der Einkommen und eine »gerechte« Besteuerung diene. ${ }^{149}$ Aus dieser Warte wird auch die Aussage des Bundesfinanzhofes, komplexe Sachverhalte rechtfertigten komplexes Recht, ${ }^{150}$ überzeugend.

Aus verhaltenswissenschaftlicher Perspektive gibt es im Hinblick auf Komplexität einen weiteren interessanten Befund. In einem von Psychologen in Chemnitz durchgeführten Experiment wurde die Komplexität ${ }^{151}$ einer Entscheidungssituation variiert. ${ }^{152}$ Dann wurden als abhängige Variablen die Akzeptanz des Ratschlages eines Beraters und das diesem entgegengebrachte Vertrauen gemessen. Dabei wurde festgestellt, dass mit steigender Komplexität sowohl die Akzeptanz des Ratschlages wie auch das Vertrauen in den Berater stiegen. Das scheint freilich vor dem Hintergrund des Umstandes, dass Vertrauen die Komplexität der Entscheidungssituation zu reduzieren vermag, plausibel. ${ }^{153}$ Sind das, übertragen auf das Recht, gute Nachrichten? Angesichts einer gemeinhin als solide geltenden Ausbildung der Intermediäre - hier insbesondere der Anwälte - und aufgrund der einheitlichen Juristenausbildung in Deutschland, kann davon ausgegangen werden, dass die Rechtsbefolgung bei Einschaltung von Intermediären steigt; dass dieser Effekt sich mit steigender Komplexität verstärkt, scheint eine plausible Vermutung, die allerdings empirisch noch nachzuweisen wäre.

Letztlich kann nach diesen Erkenntnissen jedenfalls nicht gesagt werden, dass subjektiv komplexes Recht per se die Bereitschaft zur Rechtsbefolgung reduziere; im Gegenteil, es gibt sogar eher Belege für positive Effekte.

\section{e) Dogmatik: Objektivierte Adressatensicht}

Der gängigen Dogmatik zum Gebot der Normenklarheit zufolge richtet sich die Beurteilung, ob eine Norm verständlich ist, nach der Sicht des objektivierten Normadressaten.

146 Fuest, Steuerakzeptanz und Steuerwiderstand als Herausforderung in der Steuergesetzgebung (Vortrag beim Deutschen Finanzgerichtstag am 22. Januar 2007 in Köln) [Manuskript], 2007, leider ohne weiteren Nachweis. Es war dem Verfasser trotz intensiver Suche und Rückfrage beim Zitierenden nicht möglich, entsprechende empirische Evidenz zu finden. In ähnliche Richtung, allerdings ebenfalls ohne empirischen Beleg Borell/Schemmel, Steuervereinfachung, DStZ 1987, 110 (114).

147 Es ist hervorzuheben, dass die erhobene Komplexität nicht mit der hiesigen Definition übereinstimmt.

148 Forest/Sheffrin, Complexity and Compliance: An Empirical Investigation, Nat. tax jour. LV 2002, 75.

149 Forest/Sheffrin, Complexity and Compliance, Nat. tax jour. LV 2002, 75 (76); Kaplow, Accuracy, Complexity, and the Income Tax, 14 JLEO 61 (1998); vgl. auch Kaplow, A Model of the Optimal Complexity of Legal Rules, 11 JLEO 150 (1995).

151 Die Definition von Komplexität in der zitierten Untersuchung entspricht im Wesentlichen der hiesigen Definition durch Dichte und Interdependenzen.

152 Oswald/Fuchs, Readiness to trust in complex situations, 57 Swiss Journal of Psychology 248 (1998).

Vgl. dazu die Nachweise oben in Fn. 36. 
Das scheint auf den ersten Blick naheliegend zu sein. Wenn die Begründung für das Gebot der Normenklarheit ist, dass dem Normadressaten ermöglicht werden soll, sich in Einklang mit dem Gesetz $^{154} \mathrm{zu}$ verhalten, dann muss auch auf seine Kapazitäten abgestellt werden. Auf den zweiten Blick führt dies aber zu einer Reihe von unerwünschten Konsequenzen. So legt es eine Stufung der Klarheitsanforderungen nach Lebens- und Regelungsbereichen nahe - insbesondere, wenn sich der materielle Inhalt auch nach der Komplexität des Lebenssachverhalts richtet. Das heißt, für jede Norm muss erneut geprüft werden, wer ihr Adressat ist, und so kann für jede Norm ein anderer Bezugspunkt gelten. Hinzu kommt, dass der Adressatenkreis häufig nicht klar eingegrenzt werden kann (weswegen etwa der Bundesfinanzhof bei der Bestimmung von Normadressaten auf Typiken zurückgreift ${ }^{155}$ ), und in aller Regel der Verständnishorizont nicht homogen ist. Des Weiteren kann aus der Perspektive des Adressaten nicht zwischen der Komplexität der sachlichen Regelung einer Norm und der sprachlichen Verständlichkeit unterschieden werden, was bei der Bewertung der Normenklarheit zu einer Vermengung der entsprechenden inhaltlichen Kriterien und dazu führt, dass möglicherweise die Forderung nach einem einfacheren Konzept erhoben wird, obgleich eine verständlichere Sprache vonnöten wäre. ${ }^{156}$ Umgekehrt hält der Adressat eine komplexe rechtliche Regelung vielleicht für klar, weil sie sprachlich verständlich ist, und die Komplexität ihrer Regelung daher verborgen bleibt. Schließlich führt die Ausrichtung auf den Normadressaten zu einer vollständigen Subjektivierung des Gebots der Normenklarheit: es ist kein überprüfbarer, vorhersehbarer ${ }^{157}$ Maßstab mehr, sondern ein situativ und vom jeweiligen Rechtssubjekt abhängiger. Das führt letztlich dazu, dass sowohl für den Gesetzgeber, als auch für Verwaltung und Rechtsprechung ein allein auf die Adressatensicht ausgerichteter Maßstab nicht handhabbar ist.

\section{bb) Objektivierung}

Diesem Problem will die Rechtsprechung aus dem Weg gehen, indem sie sich bei der Beurteilung, ob eine Norm verständlich ist, an der »objektivierten Adressatensicht« orientiert. Während offenkundig ist, dass sie mit der »Objektivierung« der Adressatensicht verhindern will, sich auf das Verständnis des unverständigsten Adressaten festlegen zu müssen, ist völlig unklar, wie die Adressatensicht objektiviert wird. ${ }^{158}$ Denkbar ist allenfalls, dass sie den Bezugspunkt über eine Aggregierung der Adressaten und eine Mittelwert- oder Medianbildung zu finden sucht. Neben

154 Dass Gesetz und Recht auseinanderklaffen können und dies oftmals tun, ist oben bereits dargelegt worden, vgl. IV.3.a).

155 BFH, Beschl. v. 6. September 2006, XI R 26/04, juris, Abs. 43.

156 Siehe etwa die vom BFH etablierten Kriterien, die teilweise auf eine Überprüfung des Regelungskonzeptes, teilweise auf eine Untersuchung der sprachlichen Verständlichkeit abzielen. Unklar hinsichtlich der Frage, ob sprachliche oder regulatorische (Un-)Klarheit in den Blick genommen wird auch Karpen, Empfehlungen zur Qualitätsverbesserung von Gesetzen, ZRP 2008, 97 (99). Vgl. Schröder/Würdemann, Verständlichere Gesetzessprache, ZRP 2007, 231.

157 Zur Bedeutung der Vorhersehbarkeit vgl. Sendler, Rechtsstaat im Defizit?, in: Sendler/Redeker (Hg.), Recht - Gerechtigkeit - Rechtsstaat, 103 (118 f.); vgl. auch Kreppel, Persönlichkeitsrecht und Abgabepflicht, in Schwarze/Graf Vitzthum (Hg.), Grundrechtsschutz im nationalen und internationalen Recht, 119 ff..

158 Sollte eine Gestalt wie der reasonable man des Common Law gemeint sein, so sei hier nur verwiesen auf Herbert, ${ }^{5}$ Rechtsfälle - Linksfälle. Eine Auswahl juristischer Phantasien, Göttingen 1992, 7 ff.. 
methodischen Bedenken ${ }^{159}$ sind dagegen auch aus dogmatischer Sicht erhebliche Zweifel an einer Idealisierung des Normadressaten angebracht. ${ }^{160}$ Fraglich ist nämlich, ob es mit dem Rechtsstaatsprinzip, das ja gerade den Urgrund für das Gebot der Normenklarheit bilden soll, in Einklang zu bringen ist, dass letztlich nur Bürger mit mindestens durchschnittlichen intellektuellen Fähigkeiten den Schutz des Rechtsstaates erfahren. Zugespitzt: Genügt ein Rechtsstaat für die intellektuell Beweglichen dem Rechtsstaatsprinzip? ${ }^{161}$ Ähnliches Unbehagen beschleicht einen mit Blick auf die Rechtsanwendungsgleichheit und das Sozialstaatsprinzip. So wenig wie etwa die materielle Ausstattung den Ausschlag für den Zugang zu Gerichten geben darf, ${ }^{162}$ kann der Bezugspunkt für die Verständlichkeit des Rechts von der intellektuellen Begabung abhängen. Dem ließe sich entgegen halten, dass es ja jedermann freisteht, sich an Intermediäre zu wenden. Dann aber kann man auch gleich auf deren Kenntnisse abstellen.

\section{f) Lex lata: unklare und unbekannte Normen}

Schließlich ist zu konstatieren, dass das Gebot der Normenklarheit so, wie es die herkömmliche Dogmatik versteht, nicht angewendet oder gar durchgesetzt wird: ${ }^{163}$ Das Recht nimmt seinen Maßstab nicht ernst. Das geltende positive Recht ist an vielen Stellen dermaßen komplex, dass es für den Adressaten unverständlich ist. ${ }^{164}$ Dieses Umstandes ist sich das (positive) Recht gleichsam reflexiv »bewusst«, wie eine Reihe von gesetzlichen Normen zeigt, die sich auf seine eigene Komplexität beziehen. Dennoch führt dies nur in krassen Ausnahmefällen zu einer Kassation überkomplex-unverständlicher Normen, und nicht zu einer auf eine Reduktion der Komplexität gerichteten Reaktion des Rechts. Vielmehr versuchen ergänzende (Verfahrens-)Normen, die negativen Wirkungen der Komplexität abzumildern, etwa indem Intermediäre mit der Erklärung des Rechts betraut werden.

Prominentes Beispiel ist der mit dem Jahressteuergesetz 2007 eingeführte Anspruch auf eine kostenpflichtige rechtsverbindliche Auskunft der Finanzbehörden nach $\S 89$ Abs. 2 AO. Schon vorher wurden (freiwillig) verbindliche Auskünfte erteilt, allein die Kostenpflichtigkeit wurde wie die Gesetzgebungsmotive offenlegen - angesichts der »Kompliziertheit des Steuerrechts $\aleph^{165}$ und der Befürchtung einer wachsenden Zahl von Auskunftsanträgen eingeführt. ${ }^{166}$ Dabei wird der Auskunftsanspruch keineswegs gewährt, um die Komplexität für den antragstellenden Normadressaten zu reduzieren (und eine möglicherweise drohende Verfassungswidrigkeit

159 Letztlich liegen der konkreten Bewertung keine empirischen Daten, sondern lediglich Unterstellungen des Gerichts zugrunde, was — normativ — aus objektivierter Adressatensicht klar sein müsse (Fiktion). Völlig unreflektiert bleibt dabei auch, welche Varianzen an- und hingenommen werden müssen.

160 Vgl. Böhm, Der Normmensch. Materielle und prozedurale Aspekte des Schutzes der menschlichen Gesundheit vor Umweltschadstoffen, $96 \mathrm{f}$..

161 Illustrativ dazu (allerdings am Maßstab von Art. 2 GG) Böhm, Der Normmensch. Materielle und prozedurale Aspekte des Schutzes der menschlichen Gesundheit vor Umweltschadstoffen, 96 f., 100 ff..

162 Schulze-Fielitz, in: Dreier (Hg.), Grundgesetz, Band II, Art. 20, Rz. 215 a.E. (m.w.N.).

163 So auch Papier/Möller, Das Bestimmtheitsgebot und seine Durchsetzung, AöR 122 (1997), 177 (196 ff.).

164 Man denke nur an die Verzahnung von Sachen- und Zwangsvollstreckungsrecht, etwa an die gesetzlichen Konstruktionen zu Rechtsbehelfen gegen die Vollstreckung wegen einer Geldforderung in ein Grundstück auf der Grundlage einer Grundschuld.

166 Luttermann, Normenklarheit im Steuerrecht, FR 2007, 18 (21). 
abzuwenden), ${ }^{167}$ sondern als »Dienstleistung gegenüber dem Steuerpflichtigem « ${ }^{168}$; der Anspruch zielt also auf eine Milderung der Wirkungen der Komplexität. Die Finanzverwaltung fungiert hier als Intermediär (und zwar als Intermediär besonderer Güte, weil sie im Unterschied zu den übrigen verbindliche Aussagen trifft). Weniger bekannte Normen gleicher Art finden sich auch im Sozialrecht: Nach den $\S \S 13$ ff. SGB I haben die Normadressaten Aufklärungs-, Beratungs- und Auskunftsansprüche, die ihren Ursprung ebenfalls in der hohen Komplexität des Sozialrechts haben. Auch hier hat sich der Gesetzgeber aber nicht genötigt gesehen, »im Interesse der Normenklarheit ein einfacheres Konzept $«{ }^{169} \mathrm{zu}$ entwickeln, sondern auf Intermediäre in diesem Fall die Sozialverwaltung — vertraut.

Ferner ist dem Gesetzgeber de lege lata auch bewusst, dass die Unkenntnis des (positiven) Rechts weit verbreitet ist. Davon zeugen die notariellen Beurkundungspflichten, die sicherstellen sollen, dass dem Handelnden die rechtlichen Konsequenzen seines Tuns (durch den Notar als Intermediär) bewusst gemacht werden. Dieselbe Funktion haben die den Unternehmern im Geschäftsverkehr mit Verbrauchern aufgebürdeten Hinweis- und Aufklärungspflichten. Die Begründungspflicht von Verwaltungs- und Gerichtsentscheidungen hat ebenfalls eine Klarstellungsfunktion: ${ }^{170}$ Dem Normadressaten wird nämlich der auf seinen Fall bezogene Teil des Rechts erläutert. Im Strafrecht zeigt die bloße Existenz des Verbotsirrtums, dass die Gesetzeskenntnis nicht mehr als eine Fiktion bzw. eine Verhaltensanforderung ist: Es wird gefragt, was der Täter hätte wissen müssen. ${ }^{171}$ Damit knüpft selbst das Strafrecht nicht an die Gesetzeskenntnis, sondern an Kenntnispflichten an (deren Kenntnis wiederum fingiert wird); andernfalls würden sich wohl nur Juristen strafbar machen können.

Insofern scheint es auch mit Blick auf die Einheit und Widerspruchsfreiheit der Rechtsordnung nicht sinnvoll, im Rahmen des Gebotes der Normenklarheit auf die Verständlichkeit einer gesetzlichen Norm für den Normadressaten abzustellen.

167 In einem solchen Fall läge auch die Einführung eines kostenlosen Auskunftsanspruchs näher.

168 Bundesrat, Drs. 622/06(B), S. 35.

169 BFH, Beschl. v. 6. September 2006, XI R 26/04, juris, Abs. 49; Az. BVerfG: 2 BvL 59/06.

170 Vgl. K. Towfigh, Die Pflicht zur Begründung von Verwaltungsentscheidungen nach dem deutschen und englischen Recht und ihre Europäisierung, Diss., Frankfurt am Main 2007, 13.

171 Ereignisse wie der Mannesmann-Fall, in dem sich diese Frage stellte, obwohl im Vorfeld Intermediäre zu Rate gezogen wurden, sind kuriose Ausnahmen. 


\section{Vorschlag}

Die aufgeführten Widersprüche und Probleme der gegenwärtigen Dogmatik können ausgeräumt werden, wenn man im Gebot der Normenklarheit nicht ein individuell orientiertes, sondern ein auf die Grundlagen der Staatlichkeit bezogenes, objektives Verfassungsprinzip sieht. Dementsprechend soll für die Neukonturierung des Prinzips der Normenklarheit davon ausgegangen werden, dass es nicht (nur) ein subjektives öffentliches Recht der Normadressaten ist, sondern in erster Linie ein objektives Verfassungsprinzip, das bereits greift, bevor die Norm gleichsam den innerstaatlichen Bereich hin zum Adressaten »verlässt«.

\section{Verfassungsrechtliche Herleitung}

Eine überzeugendere verfassungsrechtliche Begründung des Gebots der Normenklarheit lässt sich gewinnen, wenn man entgegen der herrschenden Sicht an Einzelentscheidungen der Rechtsprechung und an vereinzelte Stimmen in der Literatur anknüpft. ${ }^{172}$

\section{a) Demokratie}

Wenn hier eine stärker objektiv orientierte Ausrichtung des Gebots der Normenklarheit vorgeschlagen werden soll, dann erscheint es systematisch sinnvoll, den Weg des Gesetzes und den Umgang mit ihm innerhalb der staatlichen Sphäre nachzuvollziehen. Zunächst soll daher der Gesetzgeber in den Blick genommen werden, und zwar auf der untersten Ebene, also auf der des einzelnen Mandatsträgers im Parlament. ${ }^{173}$ Es ist kein Geheimnis, dass die Parlamentarier viele der Gesetzesvorlagen, über die sie abstimmen, nicht kennen oder nicht verstehen. ${ }^{174}$ Schon die schiere Menge der Gesetzgebungsvorgänge macht eine Arbeitsteilung auch in den Parlamenten unumgänglich. Darüber hinaus gibt es Vorgänge, bei denen auch die beteiligten Fachpolitiker die vorgeschlagene lex ferenda oder etwa die Spielräume, die ihnen das bestehende Recht für die neue Gesetzgebung eröffnet, nicht durchschauen. ${ }^{175}$ Bisweilen verhindert Zeitdruck eine sa-

172 Wie oben referiert etwa der Rekurs auf Gewaltentrennung, Demokratie und Justitiabilität in der Rechtsprechung des BVerfG (vgl. oben III.1), etwa in Beschl. v. 12. Januar 1967, 1 BvR 169/63, BVerfGE 21,73 (79 f.), Beschl. v. 20. Oktober 1980, 1 BvR 640/80, BVerfGE 58, 257 (277 f.), Beschl. v. 3. März 2004, 1 BvF 3/92, BVerfGE 110, 33 (53 f.), Urt. V. 27. Juli 2005, 1 BvR 668/04, BVerfGE 113, 348 (376 f.) und Beschl. v. 13. Juni 2007, 1 BvR 1550/03 u.a., NJW 2007, 2464 (2466); vgl. daneben das Sondervotum der Richterinnen Jaeger und Hohmann-Dennhardt zu BVerfG, Urt. v. 3. März 2004, 1 BvR 2378/98, 1084/99, BVerfGE 109, 279 (389) und den Vortrag der Antragsteller in diesem Verfahren, BVerfGE 109, 279 (294 f.), sowie mit anderen Schwerpunkten — bei Kunig, Das Rechtsstaatsprinzip, passim.

173 Hier wird das herrschende Demokratiemodell zugrund gelegt; vgl. zu Alternativen Petersen, Demokratie und Grundgesetz. Veränderungen des Demokratieprinzips in Art. 20 Abs. 2 GG angesichts der Herausforderungen moderner Staatlichkeit, Preprints of the Max Planck Institute for Research on Collective Goods, 2008.

174 Vgl. etwa M. Bülow (MdB), Düstere Aussichten, Süddeutsche Zeitung Magazin, Nr. 41/2007 vom 12. Oktober 2007, S. 27 ff., z.B. auf S. 30: »Wenn ich mir anschaue, wie dick der Stapel der Vorlagen ist, die jede Woche auf dem Tisch vor dem Plenarsaal liegt — nur zum Lesen allein bräuchte ich schon eine Woche. Das führt dazu, dass ich bei vielen Abstimmungen weder den Gesetzestext kenne noch wirklich weiß, worum es geht.« Ein weiteres Beispiel findet sich bei Karpen, Empfehlungen zur Qualitätsverbesserung von Gesetzen, ZRP 2008, 97 (98).

175 Das muss ohne Zweifel für die Gesetzgebung im Rahmen des StEntlG 1999/2000/2002 und die damit gesetzten $\S \S 2$ Abs. 3 S. $2-8$, 10d Abs. 1 S. 2 - 5 gelten, die Gegenstand des zitierten Vorlagebeschlusses des 
changemessene Befassung mit einem Gesetzgebungsvorschlag. ${ }^{176}$ Nach dem heute vorherrschenden Verständnis des grundgesetzlichen Demokratiebegriffs führt eine Überforderung der Abgeordneten durch die Komplexität des jeweils zu setzenden Rechts und der vielfältigen zu diesem führenden Verfahren allenfalls zu einer Verringerung der demokratischen Legitimation, ${ }^{177}$ jedoch nicht zu einer Verletzung des Demokratieprinzips. Denn Art. 20 Abs. 2 S. 1 GG ist hernach schon dann genüge getan, wenn ohne Blick auf Einzelentscheidungen das Gesetzgebungsverfahren so ausgestaltet ist, dass es zu einer durch die Abgeordneten vermittelten Rückbindung der staatlichen Gewalt an das Volk führt. Nur wenn die Überforderung der Volksvertreter den Regelfall darstellt und daher prinzipiell, d.h. nicht nur im Einzelfall, eine hinreichende Legitimation nicht mehr gewährleistet ist, kann im Hinblick auf eine Überforderung der Parlamentarier durch überkomplexes Recht von einer Verletzung des Demokratieprinzips gesprochen werden. Gleiches gilt für die Frage, ob der Grundsatz des freien Mandats der Abgeordneten gem. Art. 38 Abs. 1 S. 2 GG durch zu komplexe Gesetzesvorlagen unzulässig beschränkt wird. ${ }^{178}$ Weil diese Überlegungen im Hinblick auf das Gebot der Normenklarheit zwar weitere äußerste Grenzen markieren, indessen nicht geeignet sind, als Herleitung zu einer sinnvollen und klaren Neukonturierung und zur Herausbildung sinnvoller Prüfungsmaßstäbe beizutragen, sollen sie hier nicht weiter verfolgt werden.

\section{b) Gewaltenteilung}

$\mathrm{Zu}$ überzeugen vermag letztlich nur die Fundierung des Normenklarheitsgebots in der horizontalen Kompetenzordnung des Grundgesetzes, wie sie durch Art. 20 Abs. 1, 2 S. 1 GG mit den Grundsätzen von Gewaltenteilung und Demokratie niederlegt ist — so, wie sie vom Bestimmtheitsgebot bekannt ist. ${ }^{179}$ Die Argumentation lautet — holzschnittartig — wie folgt: Im Hinblick auf den »Umgang« mit Gesetzen ist der grundgesetzlichen Ordnung zufolge die Legislative - und als deren Kern insbesondere, aber nicht ausschließlich das Parlament — für deren Erlass zuständig, während die Rechtsprechung für die Kontrolle der Rechtsanwendung anhand

BFH sind. Die Normen sind teilweise perplex und auch im Übrigen völlig unverständlich, so dass kaum angenommen werden darf, dass sich eine Mehrheit von Parlamentariern kritisch mit ihnen auseinandergesetzt hat.

Interessante Einsichten vermittelt auch das Wortlautprotokoll der mündlichen Verhandlung in Sachen europäischer Haftbefehl (Schorkopf (Hg.), Der Europäische Haftbefehl vor dem Bundesverfassungsgericht, Tübingen 2006, 146 ff.): Wie sich im Verlaufe der Verhandlung aufgrund der Ausführungen der Abgeordneten Kauder (a.a.O., S. 243, 245 f.) und Ströbele (a.a.O., S. 247 ff.) herausstellt, hat der Deutsche Bundestag bei der Umsetzung der dem europäischen Haftbefehl zugrunde liegenden Richtlinie »im Bewusstsein normativer Unfreiheit gehandelt« (Herdegen, a.a.O, S. 187), d.h. in Unkenntnis des ihm bei der Richtlinienumsetzung zukommenden Spielraums. Vgl. zu den zeitlichen Restriktionen und deren Folgen selbst für einen erfahrenen (Straf-)Juristen Kauder, a.a.O., S. 242.

176 Ein eindrucksvolles Beispiel (das »GKV-WSG«) referiert Karpen, Empfehlungen zur Qualitätsverbesserung von Gesetzen, ZRP 2008, 97 (98).

177 So jedenfalls Borell/Schemmel, Steuervereinfachung, DStZ 1987, 110 (116); ähnlich wohl auch Luttermann, Normenklarheit im Steuerrecht, FR 2007, 18 (21), der von einer »Pflicht« der Parlamentarier spricht, »einen klaren Normbefehl zu formulieren.«

178 Das freie Mandat schützt nicht nur die Freiheit der eigentlichen Entscheidung, sondern auch die Entscheidungsfindung des Abgeordneten, etwa durch parlamentarische Informations- und Teilnahmerechte; vgl. Morlok, in: Dreier (Hg.), Grundgesetz, Art. 38, Rz. 142, 149 f..

179 Insofern erscheint es einleuchtend, zwischen den beiden Prinzipien nicht zu unterscheiden, vgl. dazu Fn. 43 (a.E.). 
des positiven Rechts verantwortlich ist. ${ }^{180}$ Wenn nun der Gesetzgeber zu komplexe Normen erlässt, dann fehlt der Judikative mangels (verständlichen) Gesetzes der Maßstab, anhand dessen sie die Gesetzmäßigkeit eines ihr vorgelegten Sachverhaltes überprüfen kann, ${ }^{181}$ und sie darf dem Gesetz auch nicht (willkürlich) einen Gehalt zuweisen. ${ }^{182}$ Dieses Szenario verletzt in mehrfacher Hinsicht Verfassungsprinzipien. ${ }^{183}$ So zeigt sich unmittelbar, dass der Grundsatz der Gewaltentrennung aus Art. 20 Abs. 2 S. 2 GG verletzt ist, weil die Gewalten ihren verfassungsmäßigen Aufgaben nicht nachgekommen sind (Legislative) oder nicht nachkommen können (Judikative). Reflex dieser Verletzung ist eine Verletzung auch des Rechtsstaatsprinzips sowie der Rechtsschutzgarantie. Das Rechtsstaatsprinzip im Sinne von Art. 20 Abs. 3 GG wird verletzt, weil die Legislative mit ihrem mangelhaften Rechtsetzungsakt gegen die verfassungsmäßige Ordnung — die Gewaltentrennung — verstoßen hat, und das so entstandene Gesetz eine Bindung der Rechtsprechung effektiv nicht zu begründen vermag. ${ }^{184}$ Schließlich wird die Garantie des Rechtsschutzes aus Art. 19 Abs. 4 S. 1 GG - und damit ein Grundrecht wie eine Grundsatznorm für die gesamte Rechtsordnung ${ }^{185}$ — verletzt, weil im geschilderten Szenario ein effektiver Rechtsschutz durch die Gerichte nicht mehr gewährleistet ist. ${ }^{186}$

Während diese Überlegungen für das Recht allgemein gelten, stellt sich das verfassungsrechtliche Problem für Normen im Bereich des öffentlichen Rechts noch verschärft. Hier treten bei der Rechtsanwendung nämlich Regierung und Verwaltung hinzu, die das positive Recht zu vollziehen haben. Normen, die so komplex sind, dass ihre Anwendung unklar wird, kann die Verwaltung aber nicht vollziehen. Da die Verwaltung zum Vollzug angehalten ist und ihr keine ei-

180 Natürlich gibt es in der Realität und auch aus diskurstheoretischer Perspektive zwischen den Gewalten und den ihnen obliegenden Aufgaben stattliche »Graubereiche«; insofern ist das hier präsentierte Modell stark vereinfacht. Hinsichtlich der Graubereiche wird man dabei immer diskutieren können, ob der Grundsatz der Gewaltentrennung bereits verletzt ist; hier interessieren aber in erster Linie die klaren Fälle, und für diese lässt die hier gewählte schematisierende Vereinfachung das eigentliche Argument plastischer werden. Vgl. zur Gewaltenteilung insgesamt Möllers, Gewaltengliederung. Legitimation und Dogmatik im nationalen und internationalen Rechtsvergleich, Habil., Tübingen 2005, insbes. 70 ff., 94 ff..

181 Vgl. speziell im Hinblick auf das Gebot der Normenklarheit BVerfG, Urt. V. 27. Juli 2005, 1 BvR 668/04, BVerfGE 113, 348 (376 f.), mit Anmerkungen von Lepsius, Anmerkung zu BVerfG, U. v. 27.07 .2005 - 1 BvR 668/04 - (Grenzen präventivpolizeilicher Telefonüberwachung), Jura 2006, 929 und Stephan, Zur Verfassungsmäßigkeit der präventiven Telefonüberwachung gem. § 33 Abs. 1 Nr. 2 und 3 NdsSOG, VBIBW 2005, 410 (412): »Eine rechtsstaatlich wirksame Kontrolle durch den Richter setzt voraus, dass er im Gesetz Anhaltspunkte für seine Kontrolle vor findet.«

182 Natürlich darf der Gesetzgeber die autoritative Auslegung der Norm in gewissem Umfang Verwaltung und Gerichten überlassen; aber dann muss er »mit den in der Regelung ausdrücklich genannten Merkmalen einen Maßstab zur Konkretisierung« formulieren (BVerfG, Beschl. v. 10. November 1981, 1 BvL 18, 19/77, BVerfGE 59, 36 [52]). Diese Voraussetzung ist bei einer überkomplexen, nicht vollziehbaren Norm nicht gegeben. Interessante Erkenntnisse liefert in diesem Zusammenhang auch die Diskussion um Rechtsregeln und Verhaltensstandards (dazu bereits oben Fn. 22), vgl. etwa Kaplow, Rules versus Standards, 42 Duke L.J. 557 (1992); Diver, The Optimal Precision of Administrative Rules, 93 Yale L.J. 65 (1983).

183 Die hier als verletzt angesehenen Verfassungsprinzipien werden von Papier/Möller, Das Bestimmtheitsgebot und seine Durchsetzung, AöR 122 (1997), 177 (179 ff.) als zum Rechtsstaatsprinzip gehörend betrachtet. Legt man diese Definition zugrunde, dann kann der Rspr. mit ihrem Rückgriff auf dieses Prinzip beigepflichtet werden; gleichwohl bleibt die konkrete Benennung der verletzten Vorschriften nach hier vertretener Auffassung vorzugswürdig.

184 Vgl. Benda, Die Wahrung verfassungsrechtlicher Grundsätze im Steuerrecht, DStZ 1984, 159 (162); Luttermann, Normenklarheit im Steuerrecht, FR 2007, 18 (21); Sobota, Das Prinzip Rechtsstaat, 496,497 f..

185 Pieroth, in: Jarass/Pieroth, GG, Art. 19 Rz. 32 ff.

186 Vgl. BVerfG, Urt. V. 27. Juli 2005, 1 BvR 668/04, BVerfGE 113, 348 (376 f.); Beschl. v. 13. Juni 2007, 1 BvR 1550/03 u.a., NJW 2007, 2464 (2466). 
gene Normverwerfungskompetenz zukommt, ist sie gezwungen, dem Gesetz einen Inhalt zu geben (der allenfalls zufällig mit dem des Gesetzgebers übereinstimmt). Die Legislative bleibt also hinter dem Auftrag der Verfassung zurück, (auch komplexe) Regelungsmaterien in die Form vollziehbarer Gesetze zu gießen, und diesem »zu wenig« steht komplementär ein »zu viel« auf Seiten der Exekutive gegenüber: ${ }^{187}$ Diese füllt die Form mit einem Gehalt, den präzise festzulegen nicht ihre Aufgabe, sondern eben die des Gesetzgebers ist. ${ }^{188}$ Beides bedeutet eine objektive Kompetenzverletzung. Dadurch wird auch eine weitere Facette des Grundsatzes der

Rechtsstaatlichkeit verletzt, denn das Gesetz vermag auch die Verwaltung nicht zu binden. ${ }^{189}$ Darüber hinaus wird das Demokratieprinzip aus Art. 20 Abs. 2 S. 1 GG verletzt, weil die staatliche Gewalt nicht mehr die Staatsbürger repräsentiert. ${ }^{190}$ Die vollziehende Gewalt ist nämlich gezwungen, letztlich ohne Legitimation selbst das Recht zu setzen, das sie vollzieht.

\section{c) Grundrechte}

Wie sich im Zusammenhang mit der Rechtsschutzgarantie schon andeutet, ist neben der objektivrechtlichen Komponente dem Gebot der Normenklarheit aber auch eine subjektive Schattierung nicht abzusprechen. $\mathrm{Zu}$ Recht sieht das Bundesverfassungsgericht bisweilen ein entsprechendes Gebot etwa (auch) »in den Grundrechten« wurzeln; gemeint ist damit der durch das jeweilige Grundrecht materiell geprägte objektive Gesetzesvorbehalt. ${ }^{191}$ Ein Gesetz, das unklar ist und damit der Verwaltung keine eindeutigen Eingriffsbefugnisse einräumt, kann dem Gesetzesvorbehalt eines Grundrechts nicht genügen. Beschränkt das Gesetz selbst das Grundrecht, dann ist es ohne Weiteres verfassungswidrig. Aber selbst wenn es nur eine Ermächtigungsgrundlage für Grundrechtseingriffe der Verwaltung darstellt, ist es verfassungswidrig, denn es gibt denknotwendig keine auf einem solchen Gesetz beruhende Maßnahme der Exekutive, die nicht am Gesetzesvorbehalt scheitert. Das Gebot der Normenklarheit ergibt sich damit gleichsam aus dem Gesetzesbegriff selbst: Ein Rechtssatz, der eine überkomplexe Regelung enthält und einen unklaren Befehl ausspricht, lässt selbst wenn er aus einem tadellosen Verfahren geboren wurde, schlicht die essentialia eines Gesetzes vermissen. ${ }^{192}$ Die Ermächtigung zur Rechtssetzung impliziert nämlich den Befehl zur Herstellung von Klarheit. ${ }^{193}$ Für diesen Zusammenhang lässt sich also sagen, dass das Gebot der Normenklarheit darauf gerichtet ist, die trügerische Maske eines nur scheinbaren Gesetzes zu beseitigen. Wichtig ist aber auch hier zu sehen, dass die Herleitung

187 Kunig, Das Rechtsstaatsprinzip, 397.

188 Vgl. Möllers, Gewaltengliederung, 178 ff. mit Überlegungen zur Delegation; s. auch Fn. 182.

189 Vgl. BVerfG, Beschl. v. 13. Juni 2007, 1 BvR 1550/03, NJW 2007, 2464 (2466); Sobota, Das Prinzip Rechtsstaat, $496 \mathrm{ff}$..

190 Vgl. statt vieler Dreier, GG, Art. 20, Rz. 87; Pieroth, in: Jarass/Pieroth, GG, Art. 20 Rz. 4 ff.

191 BVerfG, Beschl. v. 3. März 2004, 1 BvF 3/92, BVerfGE 110, 33 (53): »Ermächtigungen zu Eingriffen in das Grundrecht aus Art. 10 Abs. 1 GG bedürfen nach Art. 10 Abs. 2 Satz 1 GG einer gesetzlichen Grundlage, die dem rechtsstaatlichen Gebot der Normenbestimmtheit und Normenklarheit zu entsprechen hat. Die Maßgaben, die das Bundesverfassungsgericht [...] insoweit aus Art. 2 Abs. 1 in Verbindung mit Art. 1 Abs. 1 GG entwickelt hat (vgl. BVerfGE 65, 1 [44ff., 54]), sind grundsätzlich auf die spezielle Garantie in Art. 10 GG übertragbar (vgl. BVerfGE 100, 313 [359]).« Vgl. Schnapp, in: v. Münch/Kunig, Grundgesetz, Bd. 2, Art. 20, Rz. 24 a.E.; Kunig, Das Rechtsstaatsprinzip, 461.

192 Vgl. zur Rechtsquellenlehre und zum Gesetzesbegriff etwa Maurer, ${ }^{16}$ Allgemeines Verwaltungsrecht, München 2006, 63 ff., 68 ff. (m.w.N.).

193 Kunig, Das Rechtsstaatsprinzip, 461. Vgl. Sobota, Das Prinzip Rechtsstaat, 496, 497 f.. 
aus dem Gesetzesvorbehalt eines konkreten Grundrechts mit seinen subjektiv-rechtlichen Aspekten letztlich objektive Verfassungsprinzipien schützt und sich an die staatlichen Gewalten richtet, denn es geht um die Frage, ob objektiv eine ausreichende Ermächtigungsgrundlage vorliegt, nicht darum, ob eine subjektive Rechtsverletzung festzustellen ist. Mit dem angedeuteten subjektiven Einschlag bei der Rechtsschutzgarantie und beim Gesetzesvorbehalt hat die Ausrichtung des Gebots der Normenklarheit auf den Normadressaten schon ihr Bewenden. Eine Grundlage für einen darüber hinaus gehenden, dezidiert subjektiven Gehalt gibt es nicht. ${ }^{194}$

\section{Inhalt}

Vor der Folie dieser verfassungsrechtlichen Herleitung lässt sich nun auch unproblematisch das materielle Kriterium zur Bestimmung der Klarheit einer Norm benennen: Es ist dies die Vollziehbarkeit. ${ }^{195}$ Danach verstößt die Komplexität einer Norm - ähnlich wie beim Kriterium der Vollstreckbarkeit des Tenors einer gerichtlichen Entscheidung - ganz allgemein formuliert erst dann gegen das Gebot der Normenklarheit, wenn ihretwegen der Normbefehl nicht mehr eindeutig und daher nicht vollziehbar ist (etwa wenn eine gehäufte Verwendung unbestimmter Rechtsbegriffe oder widersprüchliche Rechtsfolgenanordnungen festzustellen sind ${ }^{196}$ ). Damit ist ein Begriff gefunden, der eine Systematisierung der bereits entwickelten Kriterien erlaubt. Es geht also nicht in erster Linie um eine Nachvollziehbarkeit der gesetzlichen Regelung für den Normadressaten, damit dieser daraus das Recht entfalten und es befolgen kann, sondern um eine Verständlichkeit des Gesetzes für all jene, die es vollziehen und den Vollzug kontrollieren (das sind neben den Gerichten auch Rechtsanwälte in ihrer Funktion als unabhängige Organe der Rechtspflege ${ }^{197}$ ) — und denen mit dem Vollzug auch die Vermittlung des aus dem Gesetz gewonnen Rechts obliegt. Wenn auch das Recht den Menschen zu dienen bestimmt ist: Gesetze sind für Juristen gemacht.

Wie verhält sich nun die hier vorgeschlagene Interpretation des Gebots der Normenklarheit zu den bisher in der Rechtsprechung für die Bewertung der Normenklarheit entwickelten Kriterien? Konsistenz ${ }^{198}$ ist ein unverzichtbares ${ }^{199}$ Merkmal von Normen, weil der Gesetzesvollzug anders unmöglich ist. Umgekehrt sind Fehleranfälligkeit ${ }^{200}$ und redaktionelle Ungenauigkeiten ${ }^{201}$, Unübersichtlichkeit $^{202}$ sowie allgemein die Erschwerung des intellektuellen Zugangs ${ }^{203}$ zwar

194 So auch Papier/Möller, Das Bestimmtheitsgebot und seine Durchsetzung, AöR 122 (1997), 177 (188).

195 In eine ähnliche Richtung argumentiert bereits Goeckel, Die Grundsätze des Rechtsstaats, 55. Vgl. zur Vollziehbarkeit auch Sendler, Rechtsstaat im Defizit?, in: Sendler/Redeker (Hg.), Recht — Gerechtigkeit — Rechtsstaat, 103 (115, 116 f.).

196 BFH, Beschl. v. 6. September 2006, XI R 26/04, juris, Abs. 54.

197 Vgl. § 1 BRAO.

198 Vgl. etwa BVerfG, Urt. v. 15. Juli 2003, 2 BvF 6/98, BVerfGE 108, 169 (181); BFH, Beschl. v. 6. September 2006, XI R 26/04, juris, Abs. 62.

199 Vgl. zu Bereichen des Rechts, in denen Inkonsistenz sinnvoll sein kann Engel, Inconsistency in the Law, in: Engel/Daston (Hg.), Is there Value in Inconsistency?, $221 \mathrm{ff}$. .

200 Vgl. BVerfG, Beschl. v. 3. März 2004, 1 BvF 3/92, BVerfGE 110, 33 (64).

201 Vgl. etwa BVerfG, Beschl. v. 13. September 2005, 2BvF 2/03, BVerfGE 114, 196 (236).

202 BFH, Beschl. v. 6. September 2006, XI R 26/04, juris, Abs. 54.

203 BFH, Beschl. v. 6. September 2006, XI R 26/04, juris, Abs. 62. 
Charakteristika schlechten Rechts und Ärgernisse, die den Gesetzesvollzug (unnötig) erschweren; ${ }^{204}$ soweit sie ihn allerdings nicht verhindern sind sie für die Prüfung der Komplexität der Regelung einer Norm ohne Belang. Damit entfällt gleichzeitig das kaum zu lösende Problem, wie etwa die Fehleranfälligkeit bestimmt werden soll. Allerdings ist dadurch nichts darüber gesagt, wie mit der Verwendung schwer verständlicher Sprache $e^{205}$ — und in der Folge etwa mit der darauf beruhenden Erschwerung des intellektuellen Zugangs - umzugehen ist. Im Einklang mit den bisherigen Ausführungen wird man sich jedenfalls der Meinung anschließen können, der Gesetzgeber dürfe nicht »leere, beliebig handhabbare Worthülsen« erlassen, ${ }^{206}$ weil auch diese nicht vollziehbar sind. Polytelie stellt keine unerlaubte Eigenschaft einer Norm dar, solange die konfligierenden Ziele mit herkömmlicher Methodik systematisiert, hierarchisiert und so aufgelöst werden können, dass im Einzelfall eine klare Lösung verbleibt. Verständlich wird dann auch, warum das Bundesverfassungsgericht es genügen lässt, wenn der Gesetzgeber »der Rechtsprechung mit den in der Regelung ausdrücklich genannten Merkmalen einen Maßstab zur Konkretisierung« an die Hand gibt. ${ }^{207}$ Nicht mehr auf die Frage der Vollziehbarkeit zu beziehen sind die von der Rechtsprechung zur Bewertung der Normenklarheit aufgestellten Kriterien der Eingriffsintensität und der Eigenart der Lebenssachverhalte. ${ }^{208}$ Sie liegen damit außerhalb des nach der geschilderten Herleitung von der Verfassung beschriebenen Anwendungsbereichs des Gebots der Normenklarheit. Soll mit ihnen die Verfassungswidrigkeit einer Norm begründet werden, so bedarf dies einer Fundierung etwa durch die herkömmliche Grundrechtsdogmatik.

\section{Bezugspunkt}

Ausgehend vom Inhalt des Gebots der Normenklarheit liegt es nahe, als Bezugspunkt für die Beurteilung der Vollziehbarkeit einer Norm entgegen der herrschenden Meinung in Rechtsprechung und Literatur ${ }^{209}$ auf Juristen — oder in der hier eingeführten Terminologie allgemeiner auf Intermediäre - abzustellen. ${ }^{210}$ Während die Vollziehbarkeit als objektives Kriterium den Inhalt

204 Nach einer Auffassung kann ein schlechtes Gesetz ggf. eine »Nachbesserungspflicht« auslösen, vgl. Choi, Die Pflicht zur Beseitigung von Gesetzesmängeln,.

205 Vgl. Schröder/Würdemann, Verständlichere Gesetzessprache, ZRP 2007, 231 - dazu zynisch Möller, Verständlichere Gesetzessprache - Institutionalisierung der Sprachprüfunng im Gesetzgebungsverfahren (zu Schröder/Würdemann, ZRP 2007, 231), ZRP 2008, 100.

206 Luttermann, Normenklarheit im Steuerrecht, FR 2007, 18 (22).

207 BVerfG, Beschl. v. 10. November 1981, 1 BvL 18, 19/77, BVerfGE 59, 36 (52).

208 Vgl. BVerfG, Beschl. v. 20. Oktober 1980, 1 BvR 640/80, BVerfGE 58, 257 (277 f.); Beschl. v. 3. März 2004, 1 BvF 3/92, BVerfGE 110, 33 (53 ff.); Beschl. v. 9. April 2003, 1 BvL 1/01 u. 1 BvR 1749/01, BVerfGE 108, 52 (75); Urt. v. 19. März 2003, 2 BvL 9-12/98, BVerfGE 108, 1 (20); Beschl. v. 20. Oktober 1980, 1 BvR 640/80, BVerfGE 58, 257 (278); Beschl. v. 19. April 1978, 2 BvL 2/75, BVerfGE 48, 210 (222 f.); BFH, Beschl. v. 6. September 2006, XI R 26/04, juris, Abs. 25, 28.

209 Dazu bereits oben III.3, insbesondere Nachweise in Fn. 70.

210 Das klingt auch schon an bei Benda, Die Wahrung verfassungsrechtlicher Grundsätze im Steuerrecht, DStZ 1984, 159 (162), ohne dass dieser sich letztlich vollends dazu durchringen könnte, auf den »Spezialisten« abzustellen; ganz ähnlich wie dieser auch Duve/Weirich, Die Verständigung zwischen dem Bürger und den Juristen, in: Radtke, Die Sprache des Rechts und der Verwaltung, 119 (121 f.) und Choi, Die Pflicht zur Beseitigung von Gesetzesmängeln, $43 \mathrm{f}$. (der halbherzig, aber ausdrücklich ausspricht, dass Gesetze nicht »unbedingt« von Laien verstanden werden müssen; m.w.N.). Neben der oben ausführlich zitierten ständigen Rechtsprechung der obersten Bundesgerichte anderer Auffassung etwa Papier, Verfassungsrechtliche Grundlagen der Besteuerung, in: Brandt (Hg.), Für eine bessere Steuerrechtskultur, 25 (29). — Man könnte auch 
des Gebots der Normenklarheit beschreibt (»was?«), stellt der Jurist also gleichsam den personalen (und in diesem Sinne »subjektiven«) Bezugspunkt für die Bewertung des objektiven Kriteriums dar (»aus wessen Sicht?«). Die Frage, ob eine Norm vollziehbar ist, kann nämlich nur von im Rechtssystem Bewanderten zuverlässig beantwortet werden.

\section{a) Reduktion der Komplexität}

Sinnvoll scheint die Bewegung von der rechtssubjektsbezogenen zu einer objektivrechtlichen Bewertung des Gebots der Normenklarheit vor allem im Hinblick auf die Komplexität rechtlicher Regelungen, wie sie oben definiert wurde, und darauf, welche zentrale Bedeutung der Expertise zur Beherrschung der Komplexität zukommt. ${ }^{211}$ Die lege artis mit der Technizität des Rechts operierenden Intermediäre begegnen nämlich einer geringeren relativen Normenkomplexität, können Gesetz und Recht also besser beherrschen. Im Sinne einer einheitlichen und vorhersehbaren Bewertung der Komplexität ist hierin ein Vorteil zu sehen; ${ }^{212}$ und letztlich wird damit das Recht auch für den Laien kalkulierbarer. Ferner leuchtet die bei Beziehung auf den gemeinen Normadressaten inkonsistente Großzügigkeit der Rechtsprechung — die es genügen lassen will, wenn das Verständnis eines Gesetzes »mit herkömmlichen juristischen Methoden bewältigt werden $\ll^{213}$ kann oder wenn eine Norm ausnahmsweise sogar lediglich »dem Fachmann unter Aufbietung aller juristischen Interpretationsmöglichkeiten irgendwie verständlich « ${ }^{214}$ ist - ein, wenn man die Vermittlungsleistung ${ }^{215}$ der Intermediäre berücksichtigt. Denn für die Anstrengungen der Intermediäre beim Verständnis von Normen muss letztlich die strenge Bewertung von Vorlagebeschlüssen durch das Bundesverfassungsgericht maßstäblich sein. Darüber hinaus und ganz entscheidend wird durch die Technizität — hier vor allem juristische Dogmatik im Sinne von Begriffs- und Kategorienbildung — wie oben dargelegt die Komplexität des Rechts nicht nur kontrolliert, sondern zumindest für die zuständigen Experten sogar reduziert. Stellt man dagegen auf die Adressatensicht ab, dann wird häufig eine geringere empfundene Komplexität mit einer tatsächlich relativ höheren Komplexität bezahlt. Die bisherige Interpretation des Gebots der Normanklarheit leistet dann paradoxer Weise einer höheren relativen Komplexität Vorschub.

\section{b) Verfassungsrechtliche Gründe}

Auch die verfassungsrechtliche Fundierung stützt diese Auffassung: Da es um die Frage geht, ob mangels Vollziehbarkeit eine Verletzung des Gewaltenteilungsgrundsatzes vorliegt und damit

anders formulieren und an eine Neuinterpretation der Rede von der »objektivierten Adressatensicht « denken: diese nähme dann nicht mehr die Adressaten, sondern die Intermediäre in den Blick.

211 Dazu bereits oben II.1 und II.4.

212 Zur Bedeutung der Vorhersehbarkeit und Kalkulierbarkeit des Rechts vgl. Vgl. Sendler, Rechtsstaat im Defizit?, in: Sendler/Redeker (Hg.), Recht — Gerechtigkeit — Rechtsstaat, 103 (118 f.).

213 BVerfG, Beschl. v. 27. November 1990, 1 BvR 402/87, BVerfGE 83, 130 (145).

214 BFH, Beschl. v. 6. September 2006, XI R 26/04, juris, Abs. 43.

215 Duve/Weirich, Die Verständigung zwischen dem Bürger und den Juristen, in: Radtke, Die Sprache des Rechts und der Verwaltung, 119 (125) sprechen anschaulich davon, dass der Intermediär »die Fachsprache in die Umgangssprache umsetzen« müsse. 
um objektives Verfassungsrecht, besteht kein Raum für eine subjektive Betrachtung, etwa vom Verständnishorizont eines konkreten oder idealisierten Normadressaten aus. Prüfen müssen dies letztlich Richter nach den objektiven Kriterien des Verfassungsrechts; denn der Gesetzgeber hat diese Entscheidung hinsichtlich einer im Streit stehenden Norm bereits getroffen, während die Exekutive - wenn sie beteiligt ist - keine Normverwerfungskompetenz hat. Und diese Richter sind Juristen. ${ }^{216}$ Nicht zuletzt aufgrund der einheitlichen Juristenausbildung kann aber sogar noch vom Richter auf den Juristen generalisiert werden: Das macht ganz praktisch auch deshalb Sinn, weil Juristen nicht nur mit der Rechtsanwendung betraut sind, sondern auch an Rechts(fort)bildung und Rechtsgestaltung maßgeblichen Anteil haben; nicht zuletzt kommt ihnen auch die Aufgabe zu, dem juristischen Laien das Recht zu vermitteln, und gesetzliche Normen gleichsam zu übersetzen. ${ }^{217}$ Sie müssen also die Normen »verstehen« können. Man gewinnt damit einen einheitlichen, handhabbaren und schlüssigen Bezugspunkt zur Beurteilung der Normenklarheit: ${ }^{218}$ unabhängig von Normadressaten, Regelungsgegenständen und Lebensbereichen. $^{219}$

\section{c) Größere Realitätsnähe}

All diese Vorteile eines an Juristen geeichten Gebots der Normenklarheit vermögen freilich nicht darüber hinweg zu helfen, dass die Fiktion der Kenntnis und des Verständnisses des positiven Rechts seitens der Normadressaten ersetzt wird durch eine Fiktion der Kenntnis und des Verständnisses des positiven Rechts seitens der Juristen, und dass auch Juristen — man denke nur an die Fachgerichtsbarkeiten oder an Fachanwälte - keine homogene Gruppe bilden. Die Subjektivität des Bezugspunktes lässt sich auch hiernach also nicht gänzlich aufheben. Und doch verspricht die auf Juristen bezogene Sicht eine größere Realitätsnähe, da keine lebensfremde Gesetzeskenntnis und kein fernliegendes Rechtsverständnis der Normadressaten fingiert, sondern dort angesetzt wird, wo das Gesetz in aller Regel bekannt sein und verstanden werden muss, oder wo es zumindest zuverlässig ermittelt werden kann: bei den Juristen als Anwendern, aber eben auch als Intermediären des Rechts. Durch ein strenges Haftungsregime werden die sich an Intermediäre wendenden Normadressaten außerdem letztlich selbst dann so gestellt, als hätten sie sich adäquat informiert, wenn der Intermediär ausnahmsweise keine (ausreichende) Kenntnis vom geltenden Recht hat und vermitteln kann. Auch ist die Homogenität der Gruppe der Intermediäre größer als jene der Gruppe der Normadressaten, so dass doch — wenn schon kein ganz ein-

216 Selbst wenn Laienrichter an Entscheidungen beteiligt sind — etwa im Straf- oder im Arbeitsrecht — sind immer auch Volljuristen beteiligt, die diesen Maßstab vermitteln müssen. Außerdem wird in diesen Bereichen in aller Regel um Parlamentsgesetze gestritten, so dass ohnehin das Normverwerfungsmonopol des Bundesverfassungsgerichts greift.

217 Duve/Weirich, Die Verständigung zwischen dem Bürger und den Juristen, in: Radtke, Die Sprache des Rechts und der Verwaltung, 119 (126).

218 Dazu, dass ein solcher geboten ist Papier/Möller, Das Bestimmtheitsgebot und seine Durchsetzung, AöR 122 (1997), 177 (198 ff.).

219 Eine Ausnahme jedenfalls für das Steuerrecht wünscht sich dagegen beispielsweise Kreppel, Persönlichkeitsrecht und Abgabepflicht, in: Schwarze/Graf Vitzthum (Hg.), Grundrechtsschutz im nationalen und internationalen Recht, 119 (129). 
heitlicher, so wenigstens: - ein einheitlicherer Bezugspunkt greift. Das Problem von Fiktion und Zurechnung von Gesetzes- und Rechtskenntnis wird also nicht gelöst, aber doch gemildert.

\section{d) Ökonomische und verhaltenswissenschafliche Argumente}

Darüber hinaus verspricht der hier vorgeschlagene Bezugspunkt aus ökonomischer Sicht allokative Vorteile, weil die vom Normadressaten häufig nicht mehr zu bewältigende Komplexität des Rechts von Intermediären - Experten ${ }^{220}$ — beherrscht werden kann. Das eröffnet größere Spielräume für im Sinne der Effizienz optimal komplexe Normen. Geht man davon aus, dass Intermediären auch bei der Rechtsvermittlung eine wichtige Rolle zukommt, dann scheint es vor diesem Hintergrund auch folgerichtig, nicht der landläufigen Meinung Vorschub zu leisten, dass Gesetz und Recht immer vom Normadressaten selbst verstanden werden können müssen; auch rechtspolitisch scheint insofern eine Neuausrichtung des Gebots der Normenklarheit sinnvoll. Aufgrund einer im Ganzen soliden Juristenausbildung ist ferner nicht zu befürchten, dass das mit steigender Komplexität ebenfalls steigende Vertrauen in Berater nachteilige Konsequenzen nach sich zieht. Im Gegenteil: Da wie gezeigt ${ }^{221}$ zu erwarten ist, dass die Akzeptanz des Ratschlages von Rechtsberatern wegen der aus Sicht der Normadressaten höheren Komplexität steigt, kann durch die Rechtsvermittlung seitens der Intermediäre auch eine stärkere Harmonisierung und Internalisierung von Rechtsnormen erreicht werden. Auch in diesem Sinne tragen die »unabhängigen Organe der Rechtspflege« also zur Rechtspflege bei.

\section{e) Höhere Konsistenz der Gesamtrechtsordnung}

Ferner fügt sich das Gebot der Normenklarheit bei Zugrundelegung des hier vorgeschlagenen Bezugspunktes widerspruchsfreier in den zu beobachtenden Zustand der Gesamtrechtsordnung ein. Die erwähnten dogmatischen und methodischen Probleme einer Bewertung der Normenklarheit aus Adressatensicht und der Objektivierung dieser Adressatensicht können beim hier vorgeschlagenen Verständnis des Gebots der Normenklarheit von vornherein nicht auftreten. Darüber hinaus lassen sich etwa die Auskunftspflichten der Finanz- und Sozialverwaltung besser erklären, wenn man konzediert, dass es Normen gibt, die vom Normadressaten nicht mehr ohne Weiteres verstanden werden können. Auch erscheint die angesichts der Adressatenzentrierung vergleichsweise geringe Zahl der mangels Klarheit für verfassungswidrig erklärten Gesetze verständlich, wenn juristisch ausgebildete Experten maßstäblich sind. Dass das Bundesverfassungsgericht den Regelungsfreiraum und die vielzitierte Einschätzungsprärogative des Gesetzgebers ernst nimmt kann vor diesem Hintergrund auch dogmatisch begründet werden.

Nun ließe sich einwenden, die hier vorgeschlagene Konturierung des Normenklarheitsgebots bedeute, dass das Recht nur jenen helfe, die sich sein Verständnis leisten können. Das trifft indessen nicht zu. Soweit es um Rechte und vitale Interessen der Bürger geht, sieht das Recht verfassungsrechtlich etwa durch das Sozialstaatsprinzip gewährleistet - Unterstützung vor,

220 Vgl. D. Reisberg, Cognition: Exploring the science of mind, insbes. S. $135 \mathrm{ff}$. .

221 Dazu oben IV.3.d). 
etwa durch Beratungs- und Prozesskostenhilfe oder Ansprüche auf behördliche Auskünfte. ${ }^{222}$ Im Übrigen greifen das verfassungsrechtliche Gebot der Gewährung effektiven Rechtsschutzes und der allgemeine Justizgewährungsanspruch.

\section{f) Rechtsschutz}

Vehikel für den Rechtsschutz eines so verstandenen Gebots der Normenklarheit ist Art. 19 Abs. 4 GG in seiner subjektiv-rechtlichen Ausprägung. Ist eine Norm überkomplex und damit unklar, dann folgt wie bereits oben dargelegt aus der damit einhergehenden Verletzung des Grundsatzes der Gewaltentrennung, dass der Anspruch auf effektiven Rechtsschutz ${ }^{223}$ verletzt ist: Was das Gericht nicht versteht, das kann es auch nicht wirksam kontrollieren. Unterliegt aber die Anwendung eines Gesetzes keiner tatsächlich wirksamen Kontrolle, dann ist der Rechtsschutz des Bürgers stark eingeschränkt oder geht sogar ins Leere. Das stellt dann eine Verletzung des Anspruchs auf effektiven Rechtsschutz dar, der für sich genommen justitiabel ist. ${ }^{224}$ Aber auch wenn man (allein) die objektivrechtliche Dimension des Gebots der Normenklarheit — insbesondere die Verletzung des Gewaltentrennungsprinzips — in den Blick nimmt, ergeben sich Klagebefugnis und Anspruch aus der die Beachtung des objektiven Verfassungsrechts absichernden formellen Grundrechtsschranke des jeweils sachlich einschlägigen Freiheitsrechts. Zuständig für die Beurteilung der Normenklarheit sind auch bei dieser staatsrechtlichen Neuausrichtung des Gebots die Gerichte, bei Parlamentsgesetzen das Bundesverfassungsgericht. 


\section{Ausblick}

Die Komplexität des Rechts und der ihm zugrunde liegenden Gesetze ergibt sich aus Dichte und Interdependenzen der Normen. Sie kann aus einer rechtswissenschaftlich-objektiven oder aus einer adressatenorientiert-subjektiven Warte betrachtet werden. Komplexität stellt dabei in erster Linie ein kognitives Problem dar, mit Reflexen etwa auf den Skalen Zeit und Geld. Die Technizität der Normen reduziert die absolute Komplexität und kann die relative gleichermaßen steigern oder reduzieren. Wie die Technizität dient auch die juristische Dogmatik insbesondere mit ihrer Begriffs- und Kategorienbildung der Komplexitätsreduktion. Dagegen gilt das Gebot der Normenklarheit nicht der Komplexitätsreduktion, sondern allein der Komplexitätskontrolle. Es gründet im Prinzip der Gewaltenteilung, das in diesem Zusammenhang eng mit dem Demokratieprinzip und der Rechtsschutzgarantie verschränkt ist. Inhaltliches Kriterium für die Bestimmung der Klarheit einer Norm ist deren Vollziehbarkeit. Ob eine Norm als vollziehbar anzusehen ist, richtet sich nach dem Verständnis deutscher Juristen. Nach der hier vertreten Auffassung ist das Gebot der Normenklarheit damit insgesamt nicht adressatenorientiert-subjektiv, sondern vielmehr rechtswissenschaftlich-objektiv zu verstehen.

Die im Verfassungsrecht angelegte Lösung für das Problem einer von den Normadressaten als übermäßig empfundenen Komplexität des positiven Rechts liegt nämlich nicht in einer Vereinfachung des Rechts, sondern im Rückgriff auf Experten(wissen). Dies ist auch aus Sicht der Kognitionswissenschaften das Mittel der Wahl für den Umgang mit Komplexität. Überdies entgeht man damit dem Problem, dass das Recht nach einer Vereinfachung auf die Vielgestaltigkeit der Realität nicht mehr adäquat reagieren könnte. Ferner ist diese Lösung auch systemtheoretisch sinnvoll: Eine unmittelbar am Adressaten ansetzende Definition der Normenklarheit leistet einer Entdifferenzierung des Systems Recht Vorschub; dagegen nimmt das hier vorgeschlagene Verständnis die Ausbildung von Systemen ernst, was der Systemtheorie zufolge eine Voraussetzung dafür ist, dass die Gesellschaft mehr Komplexität verarbeiten kann. ${ }^{225}$

Das rechtswissenschaftlich-objektive Verständnis vom Gebot der Normenklarheit hat einen weiteren Vorteil: Durch das klare inhaltliche Kriterium und den einheitlichen Bezugspunkt wird es möglich, zwischen der Komplexität der Regelung und der Verständlichkeit der Sprache einer Norm zu unterscheiden; diese Unterscheidung ist aus Adressatensicht nicht möglich. Das inhaltliche Kriterium der Vollziehbarkeit bezieht sich auf die Komplexität der Regelung, die Gegenstand dieser Abhandlung ist. Auf die Frage der sprachlichen Verständlichkeit einer Norm geht der vorliegenden Beitrag indessen nicht näher ein. $\mathrm{Zu}$ deren Bewertung wären ergänzend noch sprachphilosophische und linguistische Erwägungen anzustellen. Vor der Folie des hier entwickelten Ansatzes zeichnet sich aber ab, dass als äußerste Grenze auch für die sprachliche Verständlichkeit das für den Regelungsgehalt etablierte Kriterium der Vollziehbarkeit gilt, und dass für die Bewertung auf die Intermediäre abzustellen ist. Allgemeiner wird man aus dem Entwickelten folgern können, dass die Sprache des Gesetzes nicht komplexer sein darf als seine

225 Vgl. Di Fabio, Offener Diskurs und geschlossene Systeme, 108 ff.; grundlegend Luhmann, Ausdifferenzierung des Rechts, etwa 241 ff.; daneben 35 ff., insbes. 41 f., 51 f., 80 ff.. 
Regelung, was insbesondere impliziert, dass der Gesetzgeber ein Gesetz nicht komplexer formulieren darf, als dies die Regelung erforderlich macht. Er darf also den Regelungsgehalt der Norm nicht hinter einer unverständlichen Sprache verstecken. Insofern folgt die Bewertung der sprachlichen Klarheit einer Norm der Klarheit ihrer Regelung nach, die verfassungsrechtliche Zulässigkeit der ersteren ist abhängig von letzterer. Auch hier gilt aber: nicht jede sprachlich misslungene Fassung einer Norm ist verfassungswidrig. Wie dieser Maßstab zu operationalisieren ist, kann an dieser Stelle nicht geklärt werden.

Letztlich hebt man damit nur eine ohnehin im Recht unausgesprochene normative Anforderung an den Normadressaten hervor: Wenn er das Recht nicht versteht, muss er es sich erklären lassen. Zugespitzt: Nicht das Recht muss sich bemühen, simpel daherzukommen, sondern der Adressat, es zu verstehen. Dieses Postulat soll wohlgemerkt nicht einer unnötig komplexen Gesetzgebung Feigenblatt sein; aber es soll der Legislative den erforderlichen Freiraum verschaffen, angemessen mit Rechtsnormen auf die Komplexität der Lebenssachverhalte zu reagieren. Damit gewinnt die Verantwortung der Juristen für die allgemeine Rechtsvermittlung eine größere Bedeutung; auch rückt etwa der Charakter der Anwaltschaft als unabhängigem Organ der Rechtspflege wieder stärker in den Mittelpunkt. Der verstärkte und bewusste Rückgriff auf dogmatisch versierte Intermediäre ist jedenfalls in gesetzeszentrierten Rechtssystemen die einzige nachhaltige Strategie für eine Adaptation des Rechts an das sich wandelnde und zunehmend komplexer werdende Leben. 


\section{Preprints 2008}

201. Christian Traxler / Andreas Reutter: Apportionment, Fiscal Equalization and Decentralized Tax Enforcement. 2008/21.

200. Christoph Engel, REITs ante portas. Die Anpassung des deutschen Rechts an institutionelle Investoren in den Grundstücksund Mietmärkten. 2008/20.

199. Christoph Engel, Ernst-Joachim Mestmäcker. 2008/19.

198. Andreas Glöckner, „Neurorecht“ ohne Psychologie? Die Rolle verhaltenswissenschaftlicher Betrachtungsebenen bei der Ableitung rechtspolitischer Empfehlungen. 2008/18.

197. Ernesto Crivelli/Klaas Staal, Size, Spillovers and Soft Budget Constraints. 2008/17.

196. Niels Petersen, The Principle of Democratic Teleology in International Law. 2008/16.

195. Markus Quirin/Martin Beckenkamp/Julius Kuhl, Giving or Taking: The Role of Dispositional Power Motivation and Positive Affect in Profit Maximization. 2008/15.

194. Andreas Glöckner/Tilmann Betsch/Nicola Schindler, Construction of Probabilistic Inferences by Constraint Satisfaction. 2008/14.

193. Carsten Burhop/Thorsten Lübbers, Cartels, managerial incentives, and productive efficiency in German coal mining, 1881-1913. 2008/13.

192. Andreas Glöckner/Tilmann Betsch, Multiple-Reason Decision Making Based on Automatic Processing. 2008/12. forthcoming in:

Journal of Experimental Psychology: Learning, Memory, and Cognition

191. Christian Bayer/Carsten Burhop, Corporate Governance and Incentive Contracts: Historical Evidence from a Legal Reform. 2008/11.

190. Hendrik Hakenes/Martin Peitz, Umbrella Branding and External Certification. 2008/10.

189. Felix Bierbrauer / Marco Sahm, Optimal Democratic Mechanisms for Taxation and Public Good Provision. 2008/9.

188. Andreas Glöckner, How Evolution Outwits Bounded Rationality. The Efficient Interaction of Automatic and Deliberate Processes in Decision Making and Implications for Institutions. 2008/8.

forthcoming in:

C. Engel \& W. Singer (Eds.), Better Than Conscious? Implications for Performance and Institutional Analysis. Strüngmann Forum Report 1. Cambridge, MA: MIT Press.

187. Remi Maier-Rigaud: International Organizations as Corporate Actors: Agency and Emergence in Theories of International Relations. 2008/7.

186. Stephan Lauermann, Price Setting in a Decentralized Market and the Competitive Outcome. 2008/6.

185. Andreas Glöckner / Tilmann Betsch, Do People Make Decisions Under Risk Based on Ignorance? An Empirical Test of the Priority Heuristic against Cumulative Prospect Theory. 2008/5.

forthcoming in:

Organizational Behavior and Human Decision Processes

184. Martin Hellwig, A Maximum Principle for Control Problems with Monotonicity Constraints. 2008/4.

183. Carsten Burhop, Pharmaceutical research in Wilhelmine Germany: The case of E. Merck. 2008/3.

182. Andreas Glöckner / Tilmann Betsch, Modeling Option and Strategy Choices with Connectionist Networks: Towards an Integrative Model of Automatic and Deliberate Decision Making? 2008/2.

forthcoming in:

Judgment and Decision Making

181. Christa Hainz / Hendrik Hakenes, The Politician and his Banker. 2008/1. 